\title{
Desdobramentos Econômicos dos Investimentos das Recentes Concessões Aeroportuárias Brasileiras
}

\section{Economic Effects of the Investments from Brazilian Airport Concessions}

\author{
Marcela da Silva Sales ${ }^{\mathrm{a}}$ \\ Admir Antonio Betarelli Junior ${ }^{b}$ \\ Weslem Rodrigues Faria ${ }^{\mathrm{b}}$
}

\begin{abstract}
Resumo: Este artigo tem como objetivo analisar os desdobramentos econômicos das concessões aeroportuárias realizadas entre 2012 e 2014 e propõe uma avaliação dos investimentos empregados na ampliação e modernização dos aeroportos brasileiros pelo Fundo Nacional da Aviação Civil (FNAC). O exercício de simulação das inversões previstas pelas concessões aeroportuárias em um horizonte de até 30 anos é realizado a partir de uma matriz de insumo-produto para ano de 2008 e conta com as informações da Secretaria de Aviação Civil. Os principais resultados alcançados projetam um provável aumento de $\mathrm{R} \$ 1$ 1,3 bilhões no PIB brasileiro, a possível criação de 282 mil ocupações diretas e indiretas no país e um acréscimo de $0,68 \%$ na arrecadação total da administração pública ao longo dos 30 anos. Por outro lado, as projeções setoriais dessas inversões indicam efeitos positivos sobre a atividade do setor de comércio, tanto em termos de produção quanto de emprego. Os resultados alcançados podem contribuir para o debate em curso sobre as concessões de transporte no Brasil ao sinalizar os desdobramentos e direções dos efeitos transmitidos no sistema produtivo brasileiro.
\end{abstract}

Palavras-chave: Concessões aeroportuárias. Investimentos de transporte. Modelo de insumo-produto.

\begin{abstract}
The main aim of this paper is to analyze the economic effects of investments scheduled by the airport concessions between 2012 and 2014, as disclosed by the Brazil's National Civil Aviation Fund (FNAC). To accomplish this task, we simulate investment shocks from an input-output model for 2008, whose simulation exercise has information from the Civil Aviation Secretariat. The main findings revealed that the volume of investments coming from airport concessions can generate an increase of $\mathrm{R} \$ 11.3$ billion on the Brazilian GDP, as well as create 282 thousand direct and indirect occupations and promote $0.68 \%$ growth in tax revenue from the public budget over these 30 years. On the other hand, the sectoral projections indicate positive effects on the output and employment of the trade sector. These results achieved can contribute

a Universidade Federal de Juiz de Fora (UFJF), Faculdade de Economia. Juiz de Fora, Minas Gerais, Brasil.

b Universidade Federal de Juiz de Fora (UFJF), Faculdade de Economia, Programa de Pós-Graduação em Economia (PPGE). Juiz de Fora, Minas Gerais, Brasil.
\end{abstract}


to the debate in course on transport concessions policies by signaling the intensities and directions of the effects transmitted on the Brazilian production system.

Keywords: Airport concessions. Investments in transportation. Input-output model.

JEL Classification: C67; L93; R42.

\section{1 lntrodução}

Os transportes constituem um dos setores prioritários para o desenvolvimento do país (MATERA, 2012). Uma adequada infraestrutura de transporte e mobilidade urbana é capaz de viabilizar cadeias produtivas e permitir o acesso a serviços. De acordo com Hirschman (1961), investir em infraestrutura é a condição central para promover o desenvolvimento econômico. Essas inversões podem alavancar o crescimento de uma economia em desenvolvimento, levando em consideração o mecanismo pelo qual o investimento gera mais investimento. Por meio de efeito completivo, a capacidade de crescimento pode ser transmitida intersetorialmente.

O ramo de estudo da economia dos transportes visa a alocação eficiente dos recursos escassos no setor de transportes com o intuito de proporcionar melhores condições no deslocamento de bens e pessoas. Nesse ramo, existem duas áreas centrais: a infraestrutura de transporte e o tipo de transporte. Infraestrutura de transporte reporta-se às rotas de transporte físicas e imóveis (planta fixada), tais como rodovias, ferrovias, vias fluviais, aeroportos, portos marítimos e terminais de rotas aéreas. A substituição dessa planta fixada requer um grande período de tempo (longo) e recursos financeiros, como nas adequações e expansões dos aeroportos brasileiros (BUTTON, 2010).

Em contrapartida, o tipo de transporte, uma planta móvel, integra os serviços prestados pelos modos de transporte, tais como caminhões, trens, aviões, navios, entre outros. Os serviços das companhias aéreas enquadram-se nessa categoria e têm por característica a redução da distância-tempo com segurança e conforto. A substituição de uma planta móvel apresenta um período relativamente menor e é relativamente barata, pois, se a prospectiva de demanda de um serviço de transporte declina, por exemplo, um avião pode ser transferido para outra rota ou em outra forma de serviço - transporte de carga (BUTTON, 2010).

Como apontado por Marchetti et al. (2001a), o setor aéreo mescla sua planta fixa com a sua correspondente planta móvel. Ainda, segundo esses autores, o setor é uma atividade estratégica para a economia, pois dinamiza a atividade turística, o setor hoteleiro, a atração e geração de negócios privados, promovendo efeitos de encadeamento das atividades produtivas. De acordo com Salgado, Vassallo e Oliveira (2010), a inserção internacional e a integração entre as regiões brasileiras depen- 
dem, em alguma medida, da modernização e capacidade do setor aéreo no país. O transporte aéreo contribui para também descentralizar o processo de desenvolvimento, principalmente em países de dimensões continentais, como o Brasil, e que sofrem com a carência de outros meios de transportes (MARCHETTI et al., 2001a).

Como o setor emprega tecnologia altamente intensiva em capital, o mesmo tem peso considerável na conta de serviços do balanço de pagamentos. O setor não só demanda por trabalhadores (geração de empregos), como estes precisam ser altamente qualificados, pois emprega tecnologia intensiva em capital e, além disso, necessita de uma estrutura permanente de geração e qualificação de pessoal para garantir a renovação do quadro de postos de trabalho. Por se tratar de um setor relacionado com a infraestrutura, necessita de constantes fluxos de investimentos (MARCHETTI et al., 2001a).

O desenvolvimento do setor aéreo está intimamente relacionado com o crescimento econômico dos países. Segundo Button (2010), a expansão do PIB de um país gera um impacto cerca de três vezes maior na aviação. O setor é conhecido por ser altamente elástico à renda, dessa forma, em períodos de crescimento econômico, o tráfego aéreo cresce mais do que proporcionalmente ao PIB, reforçando o efeito do próprio crescimento econômico (BUTTON, 2010).

Uma série de políticas de flexibilização econômica do setor aéreo brasileiro trouxeram visíveis modificações ao setor, com preços mais baixos e maior popularização. Por outro lado, houve maior concentração da operação em grandes aeroportos e perda de cobertura regional (ZIMMERMANN; OLIVEIRA, 2012). Tais fatores proporcionaram o crescimento acentuado do transporte aéreo de passageiros no Brasil nos últimos 15 anos. Essa expansão exigia adequada estrutura a fim de garantir a manutenção da qualidade do atendimento nos aeroportos. A tentativa governamental de investimento em infraestrutura se deu com o lançamento de plataformas como o Programa de Aceleração do Crescimento (PAC), em 2007, e o Programa de Investimento em Logística (PIL), em 2012, que previam investimentos no setor aéreo. Especialmente, o PAC propunha ofertar infraestrutura econômica mínima que viabilizasse um crescimento significativamente maior (SILVA; FORTUNATO, 2007). Por sua vez, o PIL é um projeto do governo federal, lançado em 15 de agosto de 2012, que visa dinamizar a economia brasileira e oferecer uma infraestrutura de transportes ainda mais integrada e moderna (BRASIL, 2015).

Apesar da evolução da última década, esse mercado apresenta um enorme potencial a ser desenvolvido. O aumento da demanda não foi, contudo, devidamente acompanhado pelo incremento das infraestruturas aeroportuária e aeronáutica (CONFEDERAÇÃO NACIONAL DO TRANSPORTE, 2015). Diante desse cenário, o governo brasileiro optou por uma parceria com a iniciativa privada para viabilizar e dar agilidade aos investimentos necessários para uma operação mais eficiente, além da oportunidade de troca de experiências e absorção de melhores práticas no setor. 
O primeiro lote de concessões contemplou os aeroportos internacionais de Brasília, Guarulhos/Cumbica e Viracopos. O segundo lote das concessões representou os aeroportos Internacional do Rio de Janeiro e o Internacional Tancredo Neves/Confins. De acordo com a Agência Nacional de Aviação Civil (ANAC, 2015), os cinco aeroportos concessionados movimentaram 95 milhões de passageiros (44,2\% do total do país). O montante total arrecadado com os leilões foi de $\mathrm{R} \$ 45,38$ bilhões (CNT, 2015). Ele será destinado ao Fundo Nacional da Aviação Civil (Fnac). O propósito desse fundo é alocar os recursos ao desenvolvimento e fomento da infraestrutura aérea brasileira.

É nesse contexto que se encontra a principal motivação deste estudo. Ou melhor, este trabalho tem como objetivo projetar os prováveis efeitos e desdobramentos econômicos dos recursos oriundos das concessões e investidos na ampliação e modernização dos aeroportos brasileiros pelo Fnac entre o período de 2012 a 2014.

A hipótese levantada é que os recursos empregados plenamente na forma de investimentos provoquem estímulos nas atividades econômicas, geração de empregos, arrecadação de impostos indiretos e compra de insumos importados, com destaques para os fornecedores de maior participação no vetor de alocação de investimentos do setor de transporte. Por considerar um sistema de setores interdependentes, os investimentos aeroportuários devem desencadear efeitos de primeira e segunda ordem nos principais indicadores macroeconômicos e setoriais. A transmissão, distribuição e intensidade desses efeitos dependem das próprias relações diretas e indiretas dos setores listados no vetor de investimentos de transporte com as demais atividades econômicas no país.

Destarte, para alcançar o principal objetivo, utilizou-se a metodologia de insumo-produto (MIP), que permite simular os choques favoráveis de investimento e obter os efeitos multiplicadores sobre a economia brasileira.

A principal contribuição deste estudo é fornecer uma análise quantitativa e detalhada dos desdobramentos das concessões aeroportuárias no Brasil, cuja temática é recente e, por essa razão, foi pouco explorada na área de economia aplicada. É interessante que os órgãos públicos e os dirigentes das concessionárias possam ter acesso a estudos que forneçam projeções e possíveis direções de como os investimentos programados nos aeroportos se distribuem entre as demais atividades econômicas, evidenciando os prováveis desdobramentos em certos indicadores macroeconômicos e os setores produtivos mais e menos beneficiados por essas inversões em um horizonte de quase 30 anos. Dessa maneira, os resultados projetados poderiam incrementar o debate em curso sobre as concessões de transporte e contribuir, em alguma medida, para as decisões e consecuções de estratégias de planejamento e política econômica no país.

Além desta introdução, este trabalho se organiza em mais quatro seções. A seção 2 destaca a importância dos investimentos em infraestrutura e transporte 
para a economia e trata do setor aeroportuário no Brasil. A seções 3 contempla a metodologia e descreve a carteira de investimentos. A seção 4 apresenta e discute os resultados. A seção 5 tece as considerações finais.

\section{Investimentos em Transporte e Economia}

Esta seção apresenta uma breve discussão teórica acerca dos efeitos gerados pelos investimentos em infraestrutura na economia e, em seguida, fornece um panorama do setor aeroportuário brasileiro com ênfase aos pontos de gargalo e saturação que abriram margem a realização das concessões desse tipo de infraestrutura de transporte à iniciativa privada. Por fim, a seção expõe e caracteriza esse primeiro lote de concessões ao setor aeroportuário no país.

\subsection{Encadeamentos e o Papel da Infraestrutura}

Os investimentos em infraestrutura podem ser vistos sob a ótica de ligação para trás e para frente (HIRSCHMAN, 1961). Tais inversões demandam grande quantidade de matérias-primas que estimulam a produção das empresas fornecedoras, o que caracteriza o efeito para trás, já os incentivos provocados pelas facilidades de transportes nos investimentos privados, devido à redução de custos e aumento de produtividade, consistem em efeito para frente.

Hirschman (1961) discute sobre a decisão de investimento entre capital fixo social (CFS), que nada mais é do que os serviços públicos (justiça, segurança, saúde e educação) e de infraestrutura (transporte, energia e comunicação), ou em atividades diretamente produtivas (ADP), que envolvem todo tipo de atividade geradora de bens e serviços, normalmente supridos pelo mercado (TOYOSHIMA; FERREIRA, 2002). Observa-se que qualquer que seja a estratégia adotada, novos investimentos, sejam privados ou públicos, serão induzidos. Assim, a decisão de qual caminho seguir dependerá da intensidade das externalidades geradas pelos investimentos em cada estratégia (SILVA; FORTUNATO, 2007).

Na Figura 1, o eixo horizontal mostra a disposição e o custo do CFS (que normalmente é fornecido pelo setor público e vai integrar o transporte como um componente principal), enquanto o eixo vertical mede o custo total das ADP (que geralmente é mensurado puramente nos critérios comerciais). A abordagem do crescimento equilibrado, de Button (2010), assume que as atividades de produção das ADP e do CFS devem crescer em conjunto (isto é, ao longo do caminho de crescimento representado pelo raio a partir da origem), passando pelas várias curvas de a a c, representando montantes sucessivamente mais elevados de ADP e CFS. 
Figura 1 - Trajetórias de crescimento equilibrado e desequilibrado

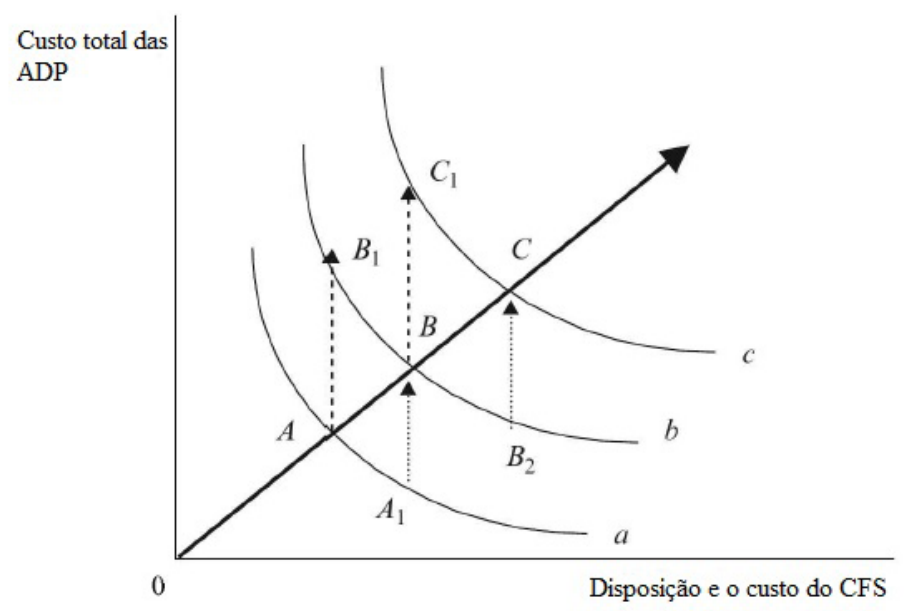

Fonte: Button (2010).

Hirschman, no entanto, argumenta que os países menos desenvolvidos, na prática, não devem seguir esse caminho, em parte devido à falta de conhecimentos técnicos necessários para assegurar que o equilíbrio seja mantido e, também, por causa de indivisibilidades inerentes aos regimes de capitais fixos sociais disponíveis. Consequentemente, o crescimento é inevitavelmente desequilibrado e pode seguir um dos dois caminhos possíveis: um com base na capacidade excedente de CFS (isto é, o caminho A-A1-B-B2-C) e o outro em cima de uma escassez de CFS (isto é, o caminho A -B1-B-C-C1) (BUTTON, 2010).

No caso do setor de transportes, este adquire insumos de outros e fornece seus serviços para a maioria, senão para a totalidade dos setores. Tais movimentos não se propagam somente em uma relação direta, mas também indiretamente, propagando efeitos por todas as atividades, incluindo a demanda final, ou seja, a expansão de um setor acaba por expandir todo o mercado (TOYOSHIMA; FERREIRA, 2002). Dessa forma, o investimento no setor de transportes (compõe o CFS) desencadeia efeitos em praticamente todas as atividades, já que esse setor demanda insumos de diversos setores e concede seus serviços para tantos outros, de forma que esse setor caracteriza-se como um setor-chave, indutor de crescimento e desenvolvimento econômico (BORGES, 2011).

Uma adequada infraestrutura de transporte e mobilidade urbana é capaz de viabilizar cadeias produtivas entre empresas e permitir o acesso a serviços. Além disso, melhorias nesse tipo de infraestrutura proporcionam ganhos de produtividade no sistema produtivo e expande o grau de acessibilidade aos mercados. Segundo Banister e Berechman (2001), uma infraestrutura adequada de transporte 
é condição essencial para o desenvolvimento de um país ou região. Uma rede bem desenvolvida é indispensável para induzir a maior integração intersetorial e regional em toda a economia. Segundo um estudo do Banco Mundial (2009), um aumento de $1 \%$ dos investimentos em transportes resulta em um crescimento de 0,57\% no PIB, demostrando uma relação direta entre infraestrutura e desenvolvimento econômico. O setor de transportes também está ligado ao desenvolvimento, pois os serviços de transportes constituem um dos fatores sistêmicos que compõem o ambiente econômico, isto é, dentre os setores que desencadeiam o processo indutivo na busca do desenvolvimento de forma eficiente, está o setor de transportes (TOYOSHIMA; FERREIRA, 2002).

\subsection{O Setor Aéreo e as Concessões dos Aeroportos no Brasil}

O Brasil é o maior mercado aéreo da América do Sul (ANAC, 2015). Segundo com dados recentes da Anac, a quantidade de passageiros pagos transportados em 2014 atingiu o maior número da história na aviação brasileira. No total, mais de 117 milhões de passageiros foram transportados em 2014, sendo quase $96 \mathrm{mi}$ lhões em voos domésticos e 21,3 milhões em voos internacionais (ANAC, 2015).

$\mathrm{Na}$ década de 1990, a crise financeira das empresas do setor aéreo em conjunto com o colapso do regime regulatório do período anterior e a falência do estado proporcionaram a desregulamentação progressiva do mercado de transportes aéreos no Brasil, o que resultou em importantes transformações na estrutura desse mercado. A flexibilização da aviação comercial se deu tanto por causa da situação crítica das empresas do setor quanto pela incapacidade do Estado de coordenar uma solução para o problema. Esperava-se que o mercado fosse capaz de selecionar as empresas mais fortes, incentivando seu crescimento em termos financeiros e tecnológicos e, além disso, eliminando as empresas frágeis. Adotando a política de flexibilização do transporte aéreo, a autoridade reguladora passou a conceder maior grau de liberdade, tal como na fixação de tarifas e descontos, entrada e saída das linhas do sistema e operação de novas companhias aéreas (BIELSCHOWSKY; CUSTÓDIO, 2011). Essa política teve a finalidade de promover uma maior liberalização do mercado, com estímulo à competitividade, visando induzir ganhos de bem-estar econômico ao consumidor (ZIMMERMANN; OLIVEIRA, 2012).

Para Zimmermann e Oliveira (2012), a política de flexibilização gerou ganhos no setor aéreo no Brasil, como queda de preços, maior eficiência operacional e competitividade das empresas. Essa política contribuiu, no longo prazo, tanto para o aumento da oferta de passagens aéreas (em outras palavras, elevação da oferta de assentos) quanto para o crescimento da demanda pelos serviços desse setor.

Também, segundo Zimmermann e Oliveira (2012), observou-se uma visivel expansão do setor, com um número maior de viagens por parte dos atuais consumidores 
e acessibilidade de novos segmentos de consumidores - aqueles passageiros que viajam pela primeira vez no modal aéreo. Em outras palavras, a demanda por passagens aéreas também sofreu aumento ao longo dos últimos 10 anos. ${ }^{1}$ Com a política de flexibilização, as companhias áreas passaram a adotar práticas de low cost, low fare, ${ }^{2}$ que inflaram ainda mais o mercado aéreo brasileiro (BETARELLI; ASSIS, 2014).

Essa política acarretou a competição entre as companhias aéreas que deixaram os preços das passagens mais acessíveis. Além disso, pode-se apontar outro motivo para justificar o crescimento da procura por passagens aéreas: o aumento do poder aquisitivo dos brasileiros nos últimos anos, pois a demanda por passagens aéreas está ligada à riqueza dos indivíduos (ALPEROVICH; MACHNES, 1994). Toda essa conjuntura se reflete no aumento da quantidade de voos, tanto domésticos quanto internacionais, ao longo da última década, como exibido no Gráfico 1.

Gráfico 1 - Evolução da quantidade de voos (2005-2014)

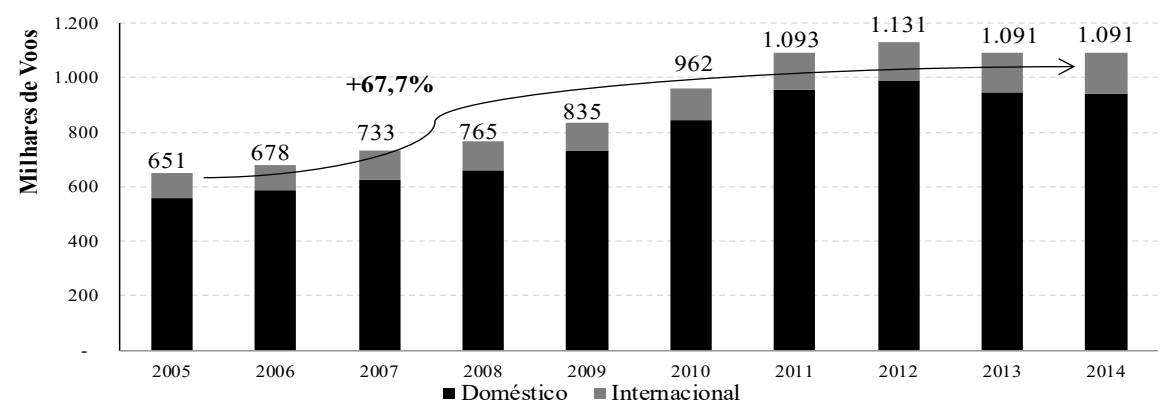

Fonte: Anuário Estatístico da Anac (2015).

Como indicado pelo Gráfico 1, entre 2005 e 2014 a quantidade total de voos teve expansão em torno de 67,7\% (ANAC, 2015). Segundo informação extraída da Empresa Brasileira de Infraestrutura Aeroportuária (BRASIL, 2016), entre 2003 e 2010 a média de passageiros nos aeroportos sofreu um incremento de $118 \%$, mais que o dobro da média mundial, que foi de $40 \%$. Além disso, de acordo com dados da Anac (2015), entre 2005 e 2014, em termos de passageiros-quilômetros pagos transportados (RPK), a demanda apresentou alta de 121,2\%, levando em conta os mercados domésticos e internacionais (ver Gráfico 2). Nesse mesmo perí

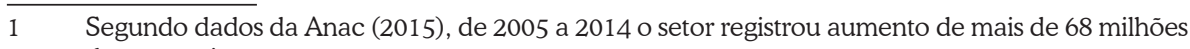
de passageiros.

2 Baixo preço, baixa tarifa: prática gerencial baseada na oferta de tarifas mais baixas a partir da simplificação do serviço, minimizando custos (CNT, 2015). 
odo, o crescimento anual do transporte aéreo doméstico representou mais de três vezes o crescimento do PIB brasileiro e mais de 13 vezes o aumento da população (ANAC, 2015).

Gráfico 2 - Evolução de crescimento de passageiros-quilômetros pagos transportados (2005 e 2014)

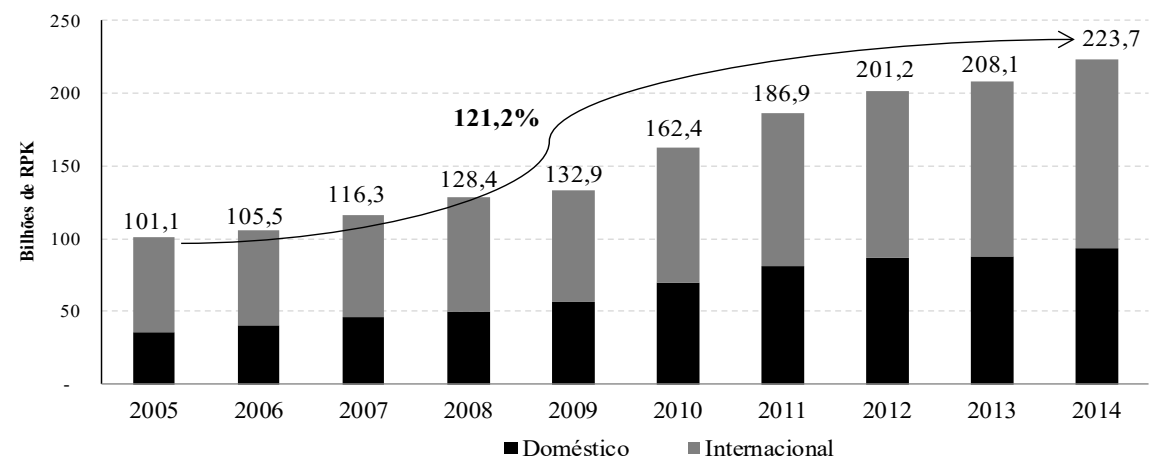

Fonte: Anuário Estatístico da Anac (2015).

Como se observa no Gráfico 3, a quantidade de passageiros pagos transportados em 2014 atingiu o maior número na história da aviação brasileira. No total, mais de 117 milhões de passageiros foram transportados em 2014, no qual foram quase 96 milhões de passageiros em voos domésticos e 21,3 milhões em voos internacionais. $\mathrm{O}$ resultado de 2014 representou um aumento acumulado de 138,6\% nos últimos 10 anos (ANAC, 2015). O segmento apresentou crescimento de $210,8 \%$ no número de passageiros entre os anos 2000 e 2014 (CNT, 2015).

Gráfico 3 - Evolução de passageiros pagos transportados entre 2005 e 2014

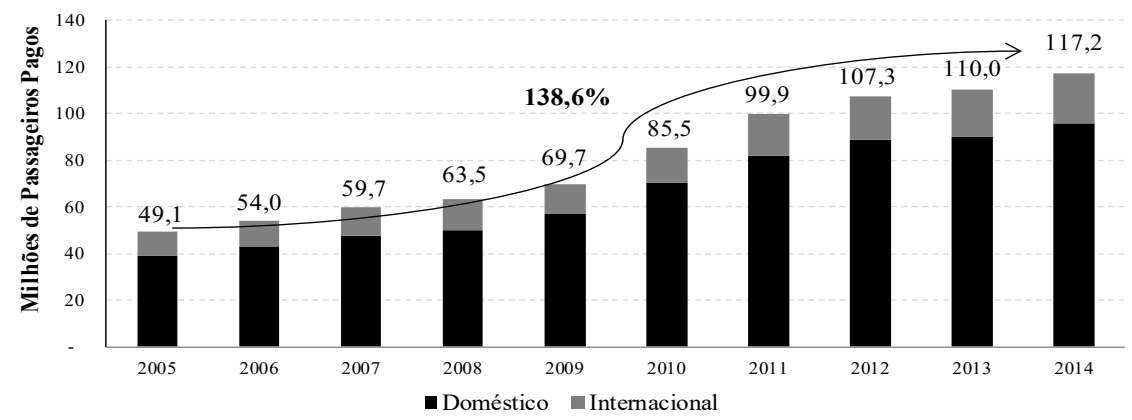

Fonte: Anuário Estatístico da Anac (2015). 
A liberalização econômica do transporte aéreo brasileiro trouxe benefícios ao setor, com preços mais baixos e maior popularização. ${ }^{3}$ Por outro lado, houve maior concentração da operação em grandes aeroportos e perda de cobertura regional (ZIMMERMANN; OLIVEIRA, 2012). Após duas décadas de medidas de liberalização econômica, o país conta com um transporte aéreo mais competitivo e eficiente, porém com as operações mais concentradas em poucos aeroportos e regiões (ZIMMERMANN; OLIVEIRA, 2012). Segundo informações da Infraero (BRASIL, 2016), em 2010 as demandas dos 15 principais aeroportos brasileiros representaram $83 \%$ da demanda total do país. Esse processo é chamado de "hubanização", em que voos de curta distância são concentrados em aeroportos centrais, denominados hubs e, a partir deles, distribui-se para as demais localidades (MARCHETTI et al., 2001b).

Pode-se recorrer a Button (2010) para explicar esse processo. A questão econômica diz respeito à tentativa de redução dos custos envolvidos no conjunto de serviços ofertados por uma empresa ou atividade em vez de considerar cada serviço especializado. Tem-se o nome de economias de custo de produção multiproduto, ou seja, economias de escopo. No setor aéreo, as propriedades derivadas dos sistemas de hub-and-spoke 4 são um bom exemplo de economias de escopo. A concentração dos processos operacionais, por exemplo, como os de manutenção e de serviços gerais em um único local, em vez de serem executadas em diferentes pontos da rede, constituem práticas que reduzem o custo médio de uma empresa de transporte aéreo ao aumentar a quantidade de pares de origem-destino servidos por um mesmo aeroporto. Outro mecanismo para aumentar a eficiência do transporte aéreo é a economia de densidade, prática que tem como intuito diminuir os custos com a consolidação das operações e a utilização de aviões maiores ou reduzir os espaços entre os assentos. Dessa forma, a empresa aérea pode alcançar uma redução de custo unitário médio e uma elevação da receita, beneficiando-se sem alterar o tempo de viagem médio ou nos aeroportos (CNT, 2015).

$\mathrm{O}$ acréscimo na demanda por serviços aéreos exige crescentes investimentos no setor com o intuito de manter a qualidade dos serviços aeroportuários brasileiros. Não obstante, a infraestrutura necessária demandada não acompanhou o crescimento do setor, que gerou pressões sobre a infraestrutura aeroportuária e, consequentemente, os gargalos existentes no setor aeroviário nacional (ZIMMER-

3 Na última década, com a liberdade tarifária e a diferenciação de preços, as empresas aéreas conseguiram baixar os valores das passagens significativamente e milhares de pessoas passaram a voar. De 2002 a 2014, os preços caíram 43,1\% (CNT, 2015). O número de viagens de avião também apresentou um aumento significativo nos últimos anos no Brasil. Em 2000, a média anual era de 0,19 por pessoa. É como se $19 \%$ da população tivesse viajado uma única vez ao ano. Em 2014, o índice atingiu 0,5, evolução de 163,2\% no período (CNT, 2015). tros de distribuição (hub) recebem e consolidam passageiros e cargas e os redistribuem para as pontas (spoke) (BUTTON, 2010). 
MANN; OLIVEIRA, 2012). Os três principais gargalos quando se trata de infraestrutura aeroportuária são: terminal de passageiros, pátio de aeronaves e pista de pouso. Esse meio de transporte implica a construção de estruturas muito especiais. Os aeroportos requerem enormes espaços e complicadas instalações de saída e entrada dos voos (BETARELLI; ASSIS, 2014).

O esforço do governo nacional para revitalizar a infraestrutura se deu principalmente mediante os programas de investimento em infraestrutura, tais como o PAC, em 2007, e o PIL em 2012. Diante do cenário de expansão e da necessidade de investimento nesse setor, ${ }^{5}$ o governo brasileiro optou por realizar uma parceria com a iniciativa privada no intuito de viabilizar e dar mais agilidade aos investimentos que adéquem a capacidade dos aeroportos à demanda atual e futura.

A criação de parcerias público-privadas deve ser incentivada a fim de estimular a construção e manutenção da infraestrutura, propiciar bem-estar aos consumidores, reduzir as despesas dos aeroportos administrados pela Empresa Brasileira de Infraestrutura Aeroportuária (Infraero) (CASTRO JÚNIOR, 2011) e retirar o transporte aéreo da inércia de realização de investimentos em infraestrutura (CNT, 2015). Desde a década de 1980, verifica-se um movimento global ${ }^{6}$ de substituição da administração pública de aeroportos pela privada. A estratégia de gestão privada está alinhada ao objetivo de conferir maior eficiência operacional, facilitar o acesso a investimentos e explorar o potencial de comercialização dos aeroportos (CNT, 2015).

O primeiro lote de concessões contemplou os aeroportos Internacional de Brasília Presidente Juscelino Kubitschek, Internacional de Guarulhos/Cumbica Governador André Franco Montoro e o Internacional de Viracopos/Campinas. O leilão desses três aeroportos ocorreu de forma simultânea na Bolsa de Valores de São Paulo no dia 6 de fevereiro de 2012. O Aeroporto Internacional de Brasília foi arrematado por $\mathrm{R} \$ 4.501$ bilhões, lance feito pelo Consórcio Inframérica Aeroportos, composto pelas empresas Infravix Participações S/A e Corporation América S/A, por um prazo de 25 anos. O Aeroporto Internacional de Guarulhos foi arrematado por $\mathrm{R} \$ 16,213$ bilhões, pelo prazo de 20 anos, pelo Consórcio Invepar (Investimentos e Participações em Infraestrutura S/A), composto pelas empresas Invepar e ACSA da África do Sul. Já o Aeroporto de Viracopos ficou em R \$3,821 bilhões, pelo prazo de 30 anos, para o consórcio Aeroportos Brasil, composto pelas

5 A CNT identificou, no Plano CNT de Transporte e Logística 2014, 200 projetos para ampliar e adequar a infraestrutura de transporte aeroportuária brasileira de passageiros e carga. Essas propostas visavam a ampliação e a construção de aeroportos, melhorias na pista e adequação da estrutura que atende o transporte de carga. Os investimentos mínimos para promover essas ações totalizam $\mathrm{R} \$ 24,90$ bilhões.

6 Antes de 1996, cidades como Copenhague (Dinamarca) e Liverpool (Reino Unido) já haviam realizado o processo de concessão. De 1997 a 2007, são exemplos Santiago (Chile), Roma (Itália), Florença (Itália), Sydney (Austrália), Budapeste (Hungria), Zurique (Suíça) e Leeds (Reino Unido) (CNT, 2015). 
instituições Triunfo Participações e Investimentos, UTC Participações e Egis Airport Operation (BRASIL, 2016).

O Segundo lote das concessões contemplou os aeroportos Internacional Galeão/Tom Jobim e o Internacional Tancredo Neves /Confins. O primeiro foi arrematado pelo Consórcio Aeroportos do Futuro, formado pela Odebrecht e Transport, com participação de 60\%, e a operadora do Aeroporto Changi, de Cingapura, com $40 \%$. O lance mínimo foi estipulado em $R \$ 4,8$ bilhões, superado em $293 \%$. $O$ vencedor do leilão ganhou a disputa com o lance de $R \$ 19$ bilhões para operar o aeroporto por 25 anos. O segundo foi arrematado pelo consórcio Aero Brasil, formado pela Companhia de Participações em Concessões (CCR), com participação de 75\%, a operadora do Aeroporto de Zurique, com 24\%, e o Munich Airport International Beteiligungs, com $1 \%$. O lance mínimo de 1,1 bilhão foi superado em $66 \%$, e o consórcio venceu o leilão com o lance de 1,8 bilhão para operar o aeroporto por 30 anos (BRASIL, 2016).

Em 2014, os cinco aeroportos concessionados movimentaram 95 milhões de passageiros, cerca de $44,2 \%$ do total do país (CNT, 2015). O total arrecadado com os leilões foi de $R \$ 45,38$ bilhões. Esse montante será destinado ao Fnac, que, por sua vez, deverá alocar os recursos a fim de promover o desenvolvimento e revitalização da infraestrutura aeroportuária e aeronáutica civil brasileira. As concessionárias são responsáveis por intervenções na infraestrutura a fim de garantir o aumento da capacidade de operação, melhorias no serviço e mais conforto aos usuários. A concessão aeroportuária é uma boa iniciativa no intuito de retomar o investimento em infraestrutura de transporte no país, uma vez que os investimentos realizados pelo governo, até então, não foram satisfatórios. Entre 2008 e 2013, foram investidos pelo governo federal e Infraero apenas $R \$ 4,19$ bilhões nesse setor, o que representa cerca de $0,1 \%$ do PIB (CNT, 2015).

\section{Metodologia}

De acordo com Miller e Blair (2009), um modelo de insumo-produto (MIP) consiste em um sistema de equações lineares, cada uma das quais descreve a distribuição de produtos de um setor em toda a economia. Em linhas gerais, seu objetivo é analisar as interdependências dos setores produtivos de uma economia em um determinado tempo e localidade (MILLER; BLAIR, 2009).

Em sua versão simples, o MIP pode ser representado matematicamente em notação matricial, como:

$$
\mathrm{X}=\mathrm{AX}+\mathrm{F}
$$


em que $X=\left\{x_{j}\right\}$ é o vetor de cada produção setorial $j ; A=\left\{a_{i j}\right\}$ é a matriz de coeficientes técnicos do setor $j$ pelo insumo $i ; \mathrm{AX}=\mathrm{Z}$ representa a matriz de consumo intermediário, cujos elementos são monetários; e $F=\left\{f_{i j}\right\}$ é a matriz de demanda final do produto $i$ e usuário final $f$. Resolvendo-se a equação 1 , tem-se:

$$
\mathrm{X}=\mathrm{BF}
$$

sendo I a matriz identidade; $\mathrm{X}$ representa a produção total necessária para atender a demanda final $\mathrm{F}$; e $(\mathrm{I}-\mathrm{A})^{-1}=\mathrm{B}$ corresponde aos requisitos diretos e indiretos pelo insumo $i$ do setor $\mathrm{j}$ por variação de uma unidade monetária de demanda final. A matriz B é conhecida como a matriz inversa de Leontief.

\subsection{Técnicas de Simulação}

Para se formular o modelo de impacto econômico da pesquisa, define-se a equação do impacto sobre o nível de produto dos setores no modelo fechado de Leontief como:

$$
\Delta \mathrm{X}=(\mathrm{I}-\mathrm{A})^{-1} \Delta f_{\mathrm{INV}}
$$

em que $\Delta f_{\text {INV }}$ representa a variação exógena da formação bruta de capital fixo (FBCF), ou seja, investimento no vetor de demanda final.

Além do efeito sobre o produto, mensuram-se os efeitos sobre outras variáveis, como emprego, impostos e importação, mediante o uso de coeficientes estruturais obtidos de uma MIP, que expressam a relação entre as variáveis de interesse e o nível de produção para cada setor da atividade econômica.

Ao se formalizar a estrutura, assume-se que os investimentos públicos representam uma variação exógena no vetor de demanda final $\left(\Delta f_{\text {INV }}\right)$ e que os níveis de valor adicionado, emprego, impostos e importação possuem uma relação fixa com os níveis de produção para cada setor de atividade. Dessa maneira, os prováveis efeitos sobre essas variáveis podem ser projetados de acordo com as seguintes expressões:

$$
\begin{aligned}
& \Delta V=C_{\mathrm{V}} \Delta X=C_{\mathrm{V}}(I-A)^{-1} \Delta f_{\mathrm{INV}} \\
& \Delta E=C_{\mathrm{E}} \Delta X=C_{\mathrm{E}}(\mathrm{I}-\mathrm{A})^{-1} \Delta f_{\mathrm{INV}}
\end{aligned}
$$




$$
\begin{gathered}
\Delta M=C_{\mathrm{M}} \Delta X=C_{\mathrm{M}}(I-A)^{-1} \Delta f_{\mathrm{INV}} \\
\Delta P=C_{\mathrm{P}} \Delta X=C_{\mathrm{P}}(I-A)^{-1} \Delta f_{\mathrm{INV}}
\end{gathered}
$$

nas quais $\Delta V, \Delta E, \Delta M$ e $\Delta P$ são, respectivamente, as mudanças sobre o valor adicionado (VA), emprego, importação e impostos sobre produção (constantes no $\mathrm{VA})$; e $C_{\nu} C_{E}, C_{M}$ e $C_{P}$ são matrizes diagonais cujos elementos representam a relação entre emprego, importação, impostos e valor bruto da produção $(X)$.

Para se sinalizar a variação total da arrecadação tributária gerada pelos choques de investimentos, deve-se também mensurar o impacto sobre os impostos indiretos. Uma vez que os impostos indiretos, como o Imposto sobre Circulação de Mercadorias e Serviços (ICMS), Imposto sobre Produtos Industrializados (IPI) e outros impostos menos subsídios, incidem conjuntamente sobre os fluxos de vendas de bens domésticos e importados, é preciso considerar as variações dessas demandas no cálculo do impacto sobre os impostos indiretos, qual seja:

$$
\Delta \mathrm{T}=C_{T}(\Delta X+\Delta M)=C_{T}\left[(I-A)^{-1} \Delta f_{\mathrm{INV}}+C_{T}\left[C_{M}(I-A)^{-1} \Delta f_{\mathrm{INV}}+C_{T M}\left[(I-A)^{-1} \Delta f_{\mathrm{INV}}\right.\right.\right.
$$

em que $\Delta \mathrm{T}$ é a mudança nos impostos indiretos em decorrência do choque de investimento, $C_{T}$ é a matriz diagonal, que contém coeficientes dos impostos indiretos em relação ao valor da produção (ICMS, IPI, outros impostos menos subsídios), $C_{M}$ é os coeficientes estruturais da importação e $C_{T M}$ é os coeficientes estruturais dos impostos sobre a importação. O último termo da equação 8 , que trata exclusivamente dos impostos sobre importação $\left(C_{T M}\left[(I-A)^{-1} \Delta f_{\mathrm{INV}}\right)\right.$, foi incluído em virtude da disponibilidade do vetor na MIP. Esse tratamento permite tornar os resultados projetados mais precisos, pois tradicionalmente se aplica o vetor total dos impostos indiretos sem qualquer tratamento diferenciado por tipos de impostos. Apesar disso, uma vez que os impostos sobre importação são pouco expressivos quando comparados aos outros tipos de impostos indiretos, esse aperfeiçoamento leva para uma pequena ou marginal diferença se comparado ao método tradicional.

Por fim, com posse dos impactos sobre o VA e os impostos indiretos, tem-se a variação do PIB brasileiro, isto é:

$$
\Delta P I B=\Delta V+\Delta T
$$


Dessa forma, pretende-se aplicar um choque de investimentos sobre o MIP e obter-se resultados em termos de emprego, produção, impostos e importações.

Ademais, é possível capturar a parcela dos efeitos diretos e indiretos sobre produção e emprego, conforme as seguintes expressões matriciais:

$$
\begin{gathered}
X^{T}=\Delta \mathrm{X}=(I-A)^{-1} \Delta f_{\mathrm{INV}} \\
X^{D}=(A) \Delta f_{\mathrm{INV}}
\end{gathered}
$$

em que $\mathrm{X}^{\mathrm{T}}$ é o efeito total e $\mathrm{X}^{\mathrm{D}}$ é a parcela de efeito direto. A partir das equações 10 e 11 , por dedução chega-se à parcela do efeito indireto $\left(X^{1}\right)$, ou melhor:

$$
X^{I}=X^{T}-X^{D}
$$

Os efeitos totais, diretos e indiretos podem ser calculados similarmente para os demais indicadores econômicos, porém considerando-se os seus correspondentes coeficientes estruturais. ${ }^{7}$

De modo geral, o MIP possibilita mensurar os efeitos sobre a produção, emprego, importações, salários, impostos e VA decorrentes de alterações na demanda final. As variações ocorridas nessas variáveis são chamadas de efeito multiplicador, ocasionado pela mudança na demanda final (DOMINGUES; CARVALHO, 2012).

Para a aplicação do modelo, utilizou-se como base de dados o MIP de 2008, projetado por Betarelli, Perobelli e Vale (2015), com algumas modificações metodológicas partindo dos procedimentos de Martinez (2014a, 2014b, 2015).

\subsection{Vetor de Choques dos Investimentos na Demanda Final}

O montante total arrecadado com os leilóes dos cinco aeroportos (cerca de $\mathrm{R} \$ 45,3$ bilhões) será destinado ao Fnac. ${ }^{8}$ Além do valor arrecadado nos leilões, que as futuras concessionárias deverão pagar anualmente ao governo federal ao longo do período de concessão dos aeroportos, o Fnac contará com aportes anuais calculados sobre a receita bruta desses aeroportos (contribuição variável) (BRASIL, 2015b). Entretanto, esta pesquisa não trata os valores referentes às con-

7 Desse modo, por conveniência, optou-se por ocultar essa decomposição em cada indicador subsequente.

8 O Fnac aplicará esses recursos visando promover o desenvolvimento e fomentar a infraestrutura aeroportuária e aeronáutica civil brasileira (CNT, 2015). 
tribuições variáveis, somente o montante destinado à ampliação da capacidade aeroportuária definido nos contratos das concessões.

Nos contratos de concessão, o governo federal estipulou um valor mínimo a ser investido pelas concessionárias nas infraestruturas aeroportuárias. As empresas privadas se comprometeram a aplicar $\mathrm{R} \$ 25,2$ bilhões, somadas as obrigações dos aeroportos concedidos, em projetos que visassem a melhorar a qualidade da infraestrutura oferecida aos usuários do sistema. A multa por descumprimento dos prazos de entrega das obras previstas nos contratos é de $R \$ 150$ milhões, mais $R \$$ 1,5 milhão por dia de atraso. As obras listadas nos contratos de concessão de cada aeroporto incluem novos terminais, ampliação de pistas, pátios, estacionamentos, vias de acesso, entre outras. Durante todo o prazo das concessões, as concessionárias deverão realizar os investimentos necessários para cumprir com os indicadores de desempenho previstos no contrato (BRASIL, 2015).

Além do total arrecadado com os leilóes e do montante dos investimentos totais programados, a Tabela 1 fornece os nomes dos consórcios vencedores, prazos das concessões e valores já investidos até março de 2015 em cada aeroporto. A soma dos investimentos totais programados, em contrato, está na ordem de R\$ 25,2 bilhões. Para adequar esse valor nominal, este foi devidamente deflacionado para 2008 (ano da matriz utilizada) utilizando-se o deflator implícito de capital fixo (IBGE, 2015). Após essa etapa, o valor resultante foi de R $\$ 19,8$ bilhões. Esse total corresponde, portanto, ao valor total do choque de investimento.

Tabela 1 - Informações sobre os aeroportos concedidos

\begin{tabular}{lcccccc}
\hline Aeroporto & $\begin{array}{c}\text { Consórcio } \\
\text { Vencedor }\end{array}$ & $\begin{array}{c}\text { Preço Final } \\
\text { (R\$ bilhões) }\end{array}$ & $\begin{array}{c}\text { Ano do } \\
\text { leilão }\end{array}$ & Prazo & $\begin{array}{c}\text { Investimentos totais } \\
\text { previstos(R\$ bilhões) }\end{array}$ & $\begin{array}{c}\text { Valor investido } \\
\text { (R\$ bilhões) }\end{array}$ \\
\hline Guarulhos & Invepar ACSA & 16.20 & 2012 & 20 & 4.60 & 3.3 \\
Brasilia & InfrAmérica & 4.50 & 2012 & 25 & 2.84 & 1.3 \\
Viracopos & Aeroportos Brasil & 3.80 & 2012 & 30 & 8.71 & 2.9 \\
Galeão & RIOGaleão & 19.00 & 2014 & 25 & 5.60 & $0.92^{*}$ \\
Confins & BH Airport & 1.80 & 2014 & 30 & 3.50 & 0.02 \\
\hline Total & & 45.30 & & & 25.20 & 8.44 \\
\hline
\end{tabular}

Fonte: elaboração própria a partir de dados da Secretaria de Aviação Civil (BRASIL, 2015c) e da CNT (2015)

Nota:" Valor investido até junho/2015

Até março de 2015, o Aeroporto Internacional de Guarulhos já tinha recebido cerca de $\mathrm{R} \$ 3,3$ bilhões em investimentos (pós-concessão). Em setembro do mesmo ano, constavam como entregues as obras do novo terminal com capacidade para atender 12 milhões de passageiros/ano - com isso a capacidade saltou de 30 milhões de passageiros/ano para 42 milhões -, a inauguração do edifício- 
-garagem, com 2644 novas vagas, 20 novas pontes e a construção de dois novos pátios para 34 aeronaves (BRASIL, 2015c). As obras do projeto de modernização dos terminais um e dois (com ampliação das áreas operacionais: check-in, raio-X, controle de passaporte, restituição de bagagem e maior oferta de lojas, principalmente em alimentação) começaram em outubro de 2014, com previsão de entrega para o segundo semestre de 2016. Esses investimentos estão na ordem de $\mathrm{R} \$ 200$ milhões. Com o término do projeto, a capacidade do aeroporto será de 48 milhões de passageiros/ano (ANDRADE, 2015).

Em Brasília, foram investidos $R \$ 1,3$ bilhão até março de 2015. Dentre as obras obrigatórias da primeira etapa estavam a construção de novo terminal com capacidade para 7 milhões de passageiros/ano, pátio para 24 aeronaves e estacionamento com 2.240 vagas. As obras entregues, entre julho de 2013 e maio de 2014, foram: terminal para 21 milhões de passageiros/ano, posições para 70 aeronaves ( 29 pontes de embarque e 41 posições remotas) e estacionamento para 2.240 vagas (BRASIL, 2015c).

No aeroporto internacional de Viracopos /Campinas, foram despendidos $\mathrm{R} \$$ 2,9 bilhões em investimentos até março de 2015. As principais obras obrigatórias descritas no contrato de concessão são: terminal para 12 milhões de passageiros/ ano; estacionamento com 4.500 vagas; construção da segunda pista de pouso/ decolagem, quando a demanda atingir 178 mil movimentos anuais. As obras entregues, entre maio e julho de 2014, foram o pátio para 72 aeronaves, 28 pontes de embarque e edifício garagem com 4.000 vagas. Encontra-se em andamento a construção de um novo terminal para atender 22 milhões de passageiros/ano (95\% concluído em outubro de 2015) (BRASIL, 2015c).

Segundo dados da Secretaria de Aviação Civil (BRASIL, 2015c), até junho de 2015 o Aeroporto Galeão contou com um aporte de $\mathrm{R} \$ 918$ milhões em investimentos. Tem-se como principais obras obrigatórias: novas instalações de embarque/desembarque de passageiros (26 pontes adicionais), pátio para 97 aeronaves (73 para Código C e 24 para Código E), estacionamento com 1.850 vagas (até dezembro de 2015) e construção da terceira pista de pouso/decolagem, quando a demanda atingir 215,1 mil movimentos anuais. Por estar em fase de adequação das infraestruturas, as principais obras como pátio e terminal de passageiros serão entregues até 30 de abril de 2016, conforme previsto no contrato de concessão.

No aeroporto de Confins, foram investidos R\$21 milhões até março de 2015. Pode-se destacar as seguintes obras obrigatórias: ampliação do terminal de passageiros com 14 pontes de embarque adicionais, pátio para 44 aeronaves (37 para Código C e sete para Código E) e construção de nova pista de pouso/decolagem com 2.500 metros (até 31 dezembro de 2010).

Apesar de apenas 33,4\% dos investimentos previstos tenham sido realizados até 2014, alguns avanços e ganhos de eficiência já podem ser observados nos ae- 
roportos concessionados, principalmente naqueles transferidos à iniciativa privada no primeiro lote. Contudo, esses benefícios não foram quantificados. Ainda que a Secretaria de Aviação Civil realize uma pesquisa de satisfação sobre os aeroportos brasileiros desde 2013, que registra maior satisfação dos passageiros em relação às instalações oferecidas, os ganhos operacionais advindos da expansão e modernização desses aeroportos ainda não foram amplamente mensurados (CNT, 2015).

Vale ressaltar que, em meados de 2015, foram anunciadas novas concessões aeroportuárias. Nessa nova etapa, pretende-se transferir à iniciativa privada a gestão dos aeroportos de Fortaleza (Pinto Martins), Salvador (Luiz Eduardo Magalhães), Florianópolis (Hercílio Luz) e Porto Alegre (Salgado Filho). Juntos, esses aeroportos foram responsáveis por 12,8\% da movimentação de passageiros em 2014 (BRASIL, 2016). Por não ter sido concluído e por restrição às informações de investimentos, esse novo ciclo de concessões não foi tratado neste trabalho.

Os recursos previstos pelas concessões aeroportuárias para investimentos não representam propriamente choques favoráveis de demanda no setor de transporte, mas naqueles setores listados no vetor de absorção de investimentos de transporte. Cada setor econômico na economia revela um comportamento diferenciado de alocação dos recursos para investimentos. Na prática, quando a atividade de transporte recebe os recursos para investimento, ampliará o número de terminais, slots e estacionamentos contratando a indústria da construção civil, a atividade de comércio, bem como comprando máquinas e equipamentos, tratores, material elétrico, entre outros. Portanto, os investimentos mínimos programados para os aeroportos concedidos não necessariamente são alocados no setor de transporte, mas também em outros setores fornecedores de insumos que contribuem para a sua formação bruta de capital fixo (FBCF).

Dessa maneira, para identificar o comportamento de alocação dos recursos de investimentos do setor de transporte, este trabalho construiu a unidade padrão setorial de investimento (UPSI) da própria atividade de transporte baseada nas matrizes de absorção de investimentos (MAI), para o ano de 2008, estimadas por Miguez et al. (2014). Isso foi feito em contraposição à utilização da unidade padrão de investimento (UPI). A vantagem de utilizar a UPSI em relação à UPI reside na consideração do comportamento específico do setor de transporte no processo de produção ao invés da média dos setores da economia.

Uma vez que o valor dos investimentos totais será plenamente aplicado em investimentos, ${ }^{9}$ este estudo realizará simulações a partir do total dos investimentos

9 Conforme os contratos das concessões, as empresas vencedoras dos leilões deverão necessariamente realizar investimentos para a melhoria da infraestrutura aeroportuária, tais como estes listados em contrato: obras no sistema de pistas (por exemplo, pavimentação de pistas de pousos e decolagens) e sistema viário; construção de novos terminais, pátio de estacionamento de aeronaves, estacionamento de veículos, pontes de embarque, entre outros (BRASIL, 2016; BRASIL, 2015c). 
previstos dos cinco aeroportos devidamente deflacionado ( $\mathrm{R} \$ 19,8$ bilhões), cujo valor será a referência para a construção do vetor de choque na demanda final da MIP de 2008. Cabe destacar que o recurso destinado para um setor específico não significa necessariamente uma repercussão direta em termos da demanda final pela produção do setor, mas sim que o setor pode ter utilizado esse recurso para investir, produzir ou aplicar como capital de giro puro.

A Tabela 2 fornece uma comparação entre vetores da UPSI e UPI. Conforme a UPSI do setor de transporte, os cinco setores mostrados no Gráfico 4 são os mais diretamente ligados à ampliação da capacidade aeroportuária. Juntos, somam $66,48 \%$ do montante total do choque, enquanto os demais setores representam $6,98 \%$ do total investido.

Tabela 2 - Diferença entre a UPI e a UPSI do setor de transporte e o vetor de choque

\begin{tabular}{|c|c|c|c|c|c|c|}
\hline Cod & Setores & MP & $\begin{array}{r}\% \\
\text { VA } \\
\end{array}$ & $\begin{array}{c}\% \\
\text { VBP }\end{array}$ & $\begin{array}{c}\% \\
\text { Exp }\end{array}$ & $\begin{array}{c}\% \\
\text { FBCF }\end{array}$ \\
\hline S1 & Agricultura, silvicultura, exploração florestal & 1.70 & 4.02 & 3.39 & $\underline{6.56}$ & 1.11 \\
\hline S2 & Pecuária e pesca & 1.93 & 1.90 & 1.88 & 1.03 & 1.97 \\
\hline S3 & Petróleo e gás natural & 1.72 & 2.14 & 2.07 & $\underline{6.01}$ & 0.00 \\
\hline S4 & Minério de ferro & 1.70 & 0.80 & 0.69 & $\underline{6.11}$ & 0.00 \\
\hline S5 & Outros da indústria extrativa & 2.02 & 0.30 & 0.37 & 0.99 & 0.00 \\
\hline S6 & Alimentos e bebidas & $\underline{2.48}$ & 2.24 & 6.49 & $\underline{12.94}$ & 0.03 \\
\hline S7 & Produtos do fumo & $\underline{2.29}$ & 0.09 & 0.21 & 1.18 & 0.00 \\
\hline S8 & Têxteis & 1.91 & 0.60 & 0.77 & 0.90 & 0.01 \\
\hline S9 & Artigos do vestuário e acessórios & 1.89 & 0.63 & 0.74 & 0.12 & 0.01 \\
\hline S10 & Artefatos de couro e calçados & 2.25 & 0.30 & 0.50 & 1.25 & 0.00 \\
\hline S11 & Produtos de couro e calçados & 2.02 & 0.36 & 0.43 & 1.11 & 0.13 \\
\hline $\mathrm{S} 12$ & Celulose e produtos de papel & 2.13 & 0.53 & 0.89 & 2.46 & 0.03 \\
\hline $\mathrm{S} 13$ & Jornais, revistas, discos & 1.74 & 0.74 & 0.71 & 0.06 & 0.01 \\
\hline S14 & Refino de petróleo e coque & $\underline{2.31}$ & 0.13 & 2.90 & 4.14 & 0.03 \\
\hline S15 & Álcool & 1.96 & 0.39 & 0.44 & 0.94 & 0.01 \\
\hline S16 & Produtos químicos & 1.93 & 0.47 & 1.53 & 1.85 & 0.05 \\
\hline S17 & Fabricação de resina e elastômeros & $\underline{2.39}$ & 0.14 & 0.54 & 0.88 & 0.00 \\
\hline S18 & Produtos farmacêuticos & 1.71 & 0.64 & 0.66 & 0.49 & 0.01 \\
\hline S19 & Defensivos agrícolas & 2.17 & 0.12 & 0.34 & 0.26 & 0.00 \\
\hline S20 & Perfumaria, higiene e limpeza & 2.16 & 0.25 & 0.45 & 0.32 & 0.00 \\
\hline $\mathrm{S} 21$ & Tintas, vernizes, esmaltes e lacas & 1.90 & 0.12 & 0.22 & 0.12 & 0.00 \\
\hline S22 & Produtos e preparados químicos diversos & 2.03 & 0.13 & 0.28 & 0.56 & 0.00 \\
\hline S23 & Artigos de borracha e plástico & 2.18 & 0.66 & 1.15 & 1.28 & 0.04 \\
\hline S24 & Cimento & $\underline{2.21}$ & 0.09 & 0.19 & 0.03 & 0.00 \\
\hline S25 & Outros produtos de minerais não-metálicos & 2.06 & 0.56 & 0.76 & 0.93 & 0.02 \\
\hline S26 & Fabricação de aço e derivados & 2.01 & 1.20 & 2.00 & 5.92 & 0.06 \\
\hline S27 & Metalurgia de metais não-ferrosos & 2.05 & 0.35 & 0.70 & 2.95 & 0.07 \\
\hline
\end{tabular}


Conclusão.

\begin{tabular}{|c|c|c|c|c|c|c|}
\hline Cod & Setores & MP & $\begin{array}{r}\% \\
\text { VA } \\
\end{array}$ & $\begin{array}{c}\% \\
\text { VBP }\end{array}$ & $\begin{array}{c}\% \\
\text { Exp }\end{array}$ & $\begin{array}{c}\% \\
\text { FBCF }\end{array}$ \\
\hline S28 & Produtos de meta - exclusive máquinas e equip. & 2.03 & 1.09 & 1.38 & 0.72 & 3.13 \\
\hline S29 & Máquinas e equip. - inclusive manut. e reparos & 2.10 & 1.18 & 1.91 & 4.15 & $\underline{12.35}$ \\
\hline S30 & Eletrodomésticos & $\underline{2.21}$ & 0.13 & 0.23 & 0.23 & 0.05 \\
\hline S31 & Máquinas para escritório e equipamentos de info. & 1.69 & 0.12 & 0.43 & 0.20 & 3.66 \\
\hline S32 & Máquinas, aparelhos e materiais elétricos & 2.09 & 0.52 & 0.90 & 1.59 & 1.05 \\
\hline S33 & Material eletrônico e equip. de comunicações & 2.06 & 0.17 & 0.62 & 1.09 & 3.27 \\
\hline S34 & Aparelhos médico-hospitalar, medida e óptico & 1.55 & 0.32 & 0.29 & 0.37 & 0.69 \\
\hline S35 & Automóveis, caminhonetas e utilitários & $\underline{2.34}$ & 0.39 & 1.66 & 2.94 & 6.80 \\
\hline S36 & Caminhões e ônibus & $\underline{2.25}$ & 0.15 & 0.57 & 1.77 & 3.98 \\
\hline S37 & Peças e acessórios para veículos automotores & $\underline{2.30}$ & 0.76 & 1.38 & 2.84 & 0.22 \\
\hline S38 & Outros equipamentos de transporte & 2.04 & 0.32 & 0.70 & 3.98 & 0.89 \\
\hline S39 & Móveis e produtos das indústrias diversas & 1.94 & 0.72 & 0.84 & 0.69 & 1.81 \\
\hline S40 & Eletricidade e gás, água, esgoto e limpeza urbana & 1.81 & 3.13 & 3.11 & 0.02 & 0.01 \\
\hline S41 & Construção & 1.72 & $\underline{4.90}$ & $\underline{4.58}$ & 0.36 & $\underline{43.30}$ \\
\hline $\mathrm{S} 42$ & Comércio & 1.42 & $\underline{12.53}$ & $\underline{8.61}$ & 4.39 & $\underline{10.80}$ \\
\hline $\mathrm{S} 43$ & Transporte, armazenagem e correio & 1.85 & $\underline{5.00}$ & 4.94 & 2.92 & 1.86 \\
\hline S44 & Serviços de informação & 1.70 & 3.80 & 3.65 & 0.33 & 0.01 \\
\hline S45 & Intermediação financeira e seguros & 1.50 & $\underline{6.80}$ & 5.23 & 0.56 & 0.01 \\
\hline S46 & Serviços imobiliários e aluguel & 1.11 & $\underline{8.15}$ & 4.27 & 0.52 & 1.25 \\
\hline S47 & Serviços de manutenção e reparação & 1.36 & 1.03 & 0.68 & 0.01 & 0.02 \\
\hline $\mathrm{S} 48$ & Serviços de alojamento e alimentação & 2.01 & 1.78 & 1.96 & 2.79 & 0.01 \\
\hline S49 & Serviços prestados às empresas & 1.55 & 4.92 & 3.94 & 5.35 & 0.50 \\
\hline S50 & Educação mercantil & 1.56 & 1.09 & 0.87 & 0.02 & 0.05 \\
\hline S51 & Saúde mercantil & 1.68 & 1.88 & 1.69 & 0.06 & 0.11 \\
\hline S52 & Outros serviços & 1.55 & 3.44 & 2.68 & 0.41 & 0.48 \\
\hline S53 & Educação pública & 1.35 & 3.85 & 2.45 & 0.01 & 0.00 \\
\hline S54 & Saúde pública & 1.50 & 2.01 & 1.57 & 0.00 & 0.00 \\
\hline S55 & Administração pública e seguridade social & 1.52 & $\underline{9.91}$ & $\underline{7.56}$ & 0.27 & 0.09 \\
\hline
\end{tabular}

Fonte: Elaboração própria a partir da matriz de Martinez (2014a, 2014b, 2015). 
Gráfico 4 - Setores com maiores participações no vetor de choque

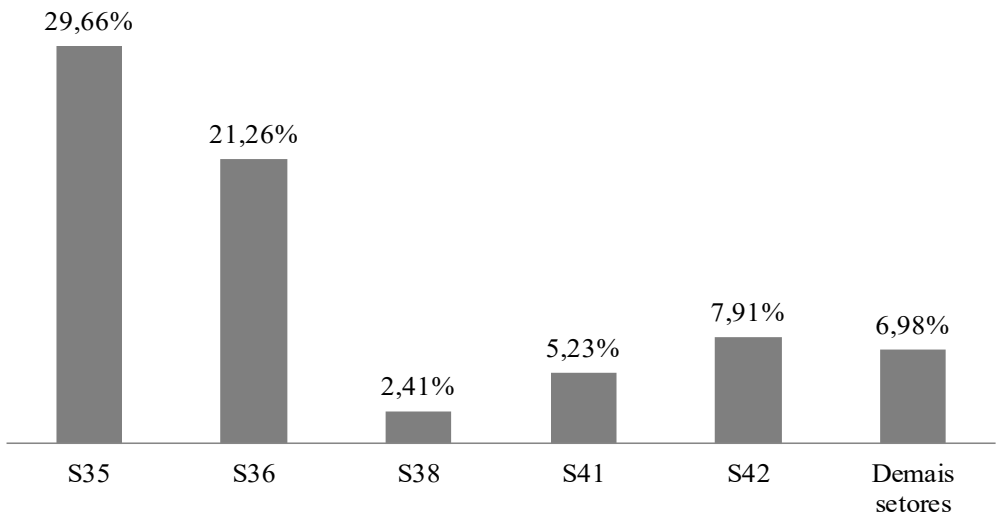

Fonte: elaboração própria.

\section{Resultados e Discussões}

Esta seção analisa as principais projeções econômicas a partir do exercício de simulação do vetor de investimentos em um modelo de insumo-produto. A estratégia de apresentação dos impactos projetados é feita em duas etapas sequenciais. A primeira etapa apresenta os efeitos sobre os principais indicadores macroeconômicos, com especial atenção para a arrecadação tributária. Em seguida, a segunda etapa analisa os impactos setoriais em termos de emprego e produção a fim de apontar os prováveis setores mais beneficiados para o lote de concessão aeroportuária.

\subsection{Projeções de Indicadores Macroeconômicos}

As projeções construídas devem ser compreendidas em um horizonte de 30 anos, uma vez que é o período máximo para que os investimentos programados sejam implementados pelas empresas concessionários nos cinco aeroportos listados da Tabela 2.

O Gráfico 5 exibe os efeitos econômicos das inversões aeroportuárias previstas sobre alguns indicadores macroeconômicos. A expansão dos investimentos ao longo desses 30 anos poderia provocar um acréscimo de aproximadamente R \$ 11,3 bilhões no PIB brasileiro, ou seja, uma variação percentual de 0,41\%. Por sua vez, a produção da atividade econômica seria 2,12 vezes maior que o choque inicial de investimentos ( $\mathrm{R} \$ 14,5$ bilhões), isto é, uma variação positiva de quase $\mathrm{R} \$ 30,8$ bilhões no país (variação de $0,58 \%$ ). Ambos os resultados compreendem efeitos de primeira e segunda ordem gerados pela ampliação da capacidade dos 
aeroportos concessionados em um horizonte de 30 anos. Ou melhor, inicialmente a atividade econômica expande sua produção para atender o choque de demanda por investimentos.

Como o MIP adota a hipótese de oferta ilimitada de insumos e em proporções fixas, a expansão inicial geraria um aumento direto na demanda por insumos intermediários. Consequentemente, as atividades fornecedoras desses insumos também expandiriam sua produção, o que pressionaria novamente a demanda das atividades setoriais, produtoras de insumos intermediários. Haveria, portanto, a transmissão e encadeamento do choque inicial dos investimentos aeroportuários ao longo do sistema produtivo brasileiro. Entretanto, a intensidade desses efeitos depende de quais foram os setores que mais sofreram inicialmente com a expansão da demanda final e como interagem com as demais atividades econômicas. $\mathrm{O}$ vetor de choque na Tabela 2 revela esses setores econômicos.

Como o impacto do emprego é computado semelhantemente ao da produção, com a ponderação dos respectivos coeficientes estruturais a variação positiva na produção nacional implicaria o aumento de postos de trabalho, tanto no mercado informal quanto no formal. ${ }^{10} \mathrm{~A}$ explicação dessa relação positiva é similar à dos insumos intermediários, ou seja, uma elevação da atividade econômica devido ao choque de investimento faz com que as empresas demandem mais mão de obra para atender a expansão de produção. Como esse aumento do nível de atividade da economia engloba a expansão da produção das atividades fornecedoras de insumos intermediários, estas também requerem fator trabalho. Tem-se, portanto, efeitos diretos e indiretos repercutidos na geração de emprego da economia. De acordo com as simulações deste trabalho, as inversões aeroportuárias gerariam cerca de 282 mil empregos diretos e indiretos no país ${ }^{11}$ em 30 anos, um acréscimo de $0,29 \%$ na economia.

10 O MIP 2008 fornece o número de ocupações por setor produtivo. Conforme o conceito do IBGE (2015), esse indicador engloba o número de trabalhadores tanto no mercado formal, quanto no informal. Além disso, para maiores detalhes sobre o cálculo do impacto de emprego, ver a equação 9 do capítulo anterior.

11 Por definição do IBGE, considera-se mercado de trabalho formal e informal. 
Gráfico 5 - Efeitos das concessões projetados sobre os principais indicadores macroeconômicos (variação em \%)

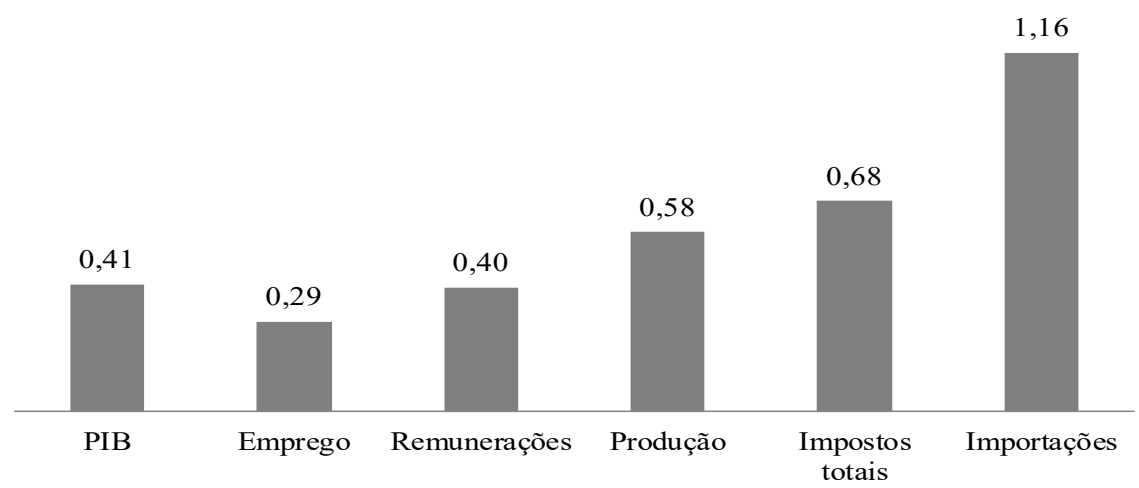

Fonte: elaboração própria.

Como o número de postos de trabalhos elevou em virtude do choque de demanda final (investimentos), a massa salarial (remunerações) também elevou. Tem-se como remunerações a soma do salário contratualmente estipulado (mensal, por hora, por tarefa, entre outros) com outras vantagens percebidas na vigência do contrato de trabalho, como horas extras, adicional noturno, adicional de periculosidade, insalubridade, comissões, percentagens, gratificações, diárias para viagem, entre outras. Como os salários são fixos em decorrência da oferta ilimitada de trabalho, a variação da massa salarial é conceitualmente resultante das oscilações do número de ocupações em um MIP. Assim, o acréscimo das remunerações na economia alcançaria quase um patamar de $\mathrm{R} \$ 5$ bilhões, o que representaria uma variação de $0,40 \%$ ao longo desses 30 anos.

Ao estimular a atividade econômica, o choque dos investimentos aeroportuários repercutiria positivamente sobre o volume de importações e de impostos arrecadados. A expansão da produção nacional, além dos insumos domésticos, requer direta e indiretamente insumos importados para atender à própria variação da demanda final. Por conseguinte, o volume de importados cresceria na ordem de $\mathrm{R} \$ 3,3$ bilhões ao longo desses 30 anos, ou melhor, uma variação de 1,16\% na economia. Cabe ressaltar que essa projeção somente considera os efeitos complementares de produção na economia, uma vez que os preços são rígidos em decorrência da hipótese de oferta ilimitada dos insumos. Assim, efeitos competitivos entre insumos domésticos e importados estão ausentes nessa projeção. Ou melhor, uma eventual perda de competitividade dos bens domésticos poderia provocar certo deslocamento de demanda em favor dos bens importados. 
Desse modo, nos resultados projetados nesta pesquisa devem ser entendidos que o nível de competitividade dos produtos domésticos permanece constante (preços rígidos) em uma economia que por suposição não exerce influência sobre os preços internacionais. Além disso, como o vetor de exportações é um componente exógeno no MIP, não é possível avaliar a repercussão do saldo comercial. Entretanto, a projeção sobre o volume de importados pode sinalizar para um provável resultado marginal da balança de comércio em decorrência da expansão da produção direcionada para atender o mercado interno. Essa é uma das vantagens de um modelo econômico de simulação como o MIP, que permite tratar apenas de um fenômeno em estudo, isolando seus efeitos na economia (BETARELLI JÚNIOR; PEROBELLI; VALE, 2015). Ou melhor, nesse caso, isolou-se a expansão do volume importado sobre a balança comercial em virtude da expansão do mercado doméstico.

Os prováveis impactos sobre a produção doméstica e a demanda de importados contribuiriam positivamente na arrecadação de impostos indiretos do orçamento público. Com os investimentos aeroportuários, os impostos indiretos separados por tipo na matriz, que são ICMS, IPI, outros impostos e impostos sobre importação, cresceriam aproximadamente $\mathrm{R} \$ 1,33$ bilhão, o que representaria $82,94 \%$ do acréscimo no total arrecadado de impostos. O resíduo representaria os impostos incidentes diretamente sobre a produção doméstica, ou melhor, um aumento de $R \$ 273$ milhões. A arrecadação total de impostos teria um incremento de $0,68 \%$ no orçamento público (cerca de $\mathrm{R} \$ 1,6$ bilhão). ${ }^{12}$ Se comparados aos investimentos previstos pelas empresas concessionárias dos cincos aeroportos brasileiros, essa variação positiva representaria $8,05 \%$ do valor investido em 30 anos.

Dessa maneira, essas projeções sobre os impostos sinalizam que as inversões previstas pelas concessões dos aeroportos poderiam contribuir para aliviar o orçamento público. Esse alívio ocorreria basicamente em duas direções. Na primeira, pela própria expansão na arrecadação dos impostos pela expansão da atividade econômica, evitando alteração da carga tributária, que compromete a própria receita tributária, conforme destaca a curva do formato $U$-invertido de Laffer. ${ }^{13} \mathrm{Na}$ segunda, os contratos dos leilóes de concessão representam a transferência dos custos generalizados das operações aeroportuárias à iniciativa privada, quando antes era de responsabilidade da administração pública. Tratam-se dos custos variáveis e fixos dos aeroportos, como para a conservação, ampliação e modernização.

Nesse tipo de infraestrutura, esses custos são crescentes em função do crescimento de demanda observado ao longo dos últimos 15 anos no Brasil. Uma vez que a oferta já não acompanhava o aumento da demanda aeroportuária no país, o

\footnotetext{
12 Vale destacar que a MIP considera os impostos separados apenas pelos tipos, que são ICMS, IPI, outros impostos, impostos sobre importação e outros impostos/subsídios sobre a produção. Portanto, tais impostos correspondem ao orçamento público como um todo, sem discriminação segundo esferas de governo.

13 Para saber mais, ver Mankiw (2009, p. 163).
} 
direito de concessão à iniciativa privada pela exploração das operações aeroportuárias, embora seja também uma transferência de receitas pelas operações, parece uma estratégia interessante à administração pública. Um dos objetivos da concessão é tornar as operações eficientes e competitivas, além das ampliações e reformas necessárias nos aeroportos e, consequentemente, tornar as operações economicamente viáveis pela redução dos custos operacionais. Dessa maneira, além de aumentar a receita tributária, poderia haver uma redução dos gastos no orçamento público, assumindo que os cinco aeroportos que fazem parte da análise apresentam déficits operacionais, quando considerada também a parcela de custos fixos.

No período anterior à concessão, a crescente demanda do setor influenciou as companhias aéreas a utilizar aeronaves de maior porte de movimentação de passageiros, sem uma contrapartida na ampliação e adequação correspondente de pistas e pátios nos principais aeroportos brasileiros, agravando, inclusive, a capacidade dos terminais de passageiros. Historicamente, o governo federal investiu pouco nos aeroportos nacionais diante de suas necessidades de modernização. Os recursos públicos, desembolsos efetuados pela União e pela Infraero, em infraestrutura aeroportuária e aeronáutica, atingiram $R$ \$3,34 bilhões em 2014, um crescimento nominal de $20 \%$ em relação ao ano de 2011 ( $\$$ 2,76 bilhões) (CNT, 2015). A mudança da administração pública pela privada nos principais aeroportos brasileiros teve $\mathrm{o}$ propósito de contornar esse cenário de investimentos insuficientes, mas também permitir que os aeroportos menores tivessem o devido aporte de recursos públicos. No caso brasileiro, a transferência de riscos do negócio não foi completa, pois a Infraero é sócia de todos os aeroportos. A participação da Infraero como acionista é de 49,0\% do capital social, com garantia de participação na governança dos aeroportos. Consequentemente, a receita operacional da Infraero nesses aeroportos concedidos reduziu, comprometendo, em parte, o aporte público em outros aeroportos brasileiros. Em 2017, os investimentos pagos pela Infraero atingiram $R \$ 535$ milhões, um decréscimo de 66\% se comparado ao montante de 2013 ( $\mathrm{R} \$ 1,6$ bilhões) (SENADO FEDERAL, 2018). Portanto, a política de concessão dos principais aeroportos pode ter contribuído para a sua redução do aporte público, porém as informações sinalizam que os montantes de investimentos nos aeroportos menores reduziram, o que contraria em alguma medida o próprio objetivo da política. 


\subsection{Projeções Setoriais}

O Gráfico 6 apresenta os setores que se beneficiariam mais com o choque de investimentos, em termos de produto e emprego. ${ }^{14}$ Nota-se que o setor de automóveis, caminhonetas e utilitários (S35) seria o mais beneficiado em termos de produção, pois representa $19,52 \%$ da variação da produção nacional. A atividade de comércio (S42), por outro lado, demandaria um maior número de empregos, ou seja, 37,57\% do aumento das ocupações em todo o país (ver Gráfico 7).

Gráfico 6 - Os 10 setores econômicos mais beneficiados pelas inversões aeroportuárias (produção)

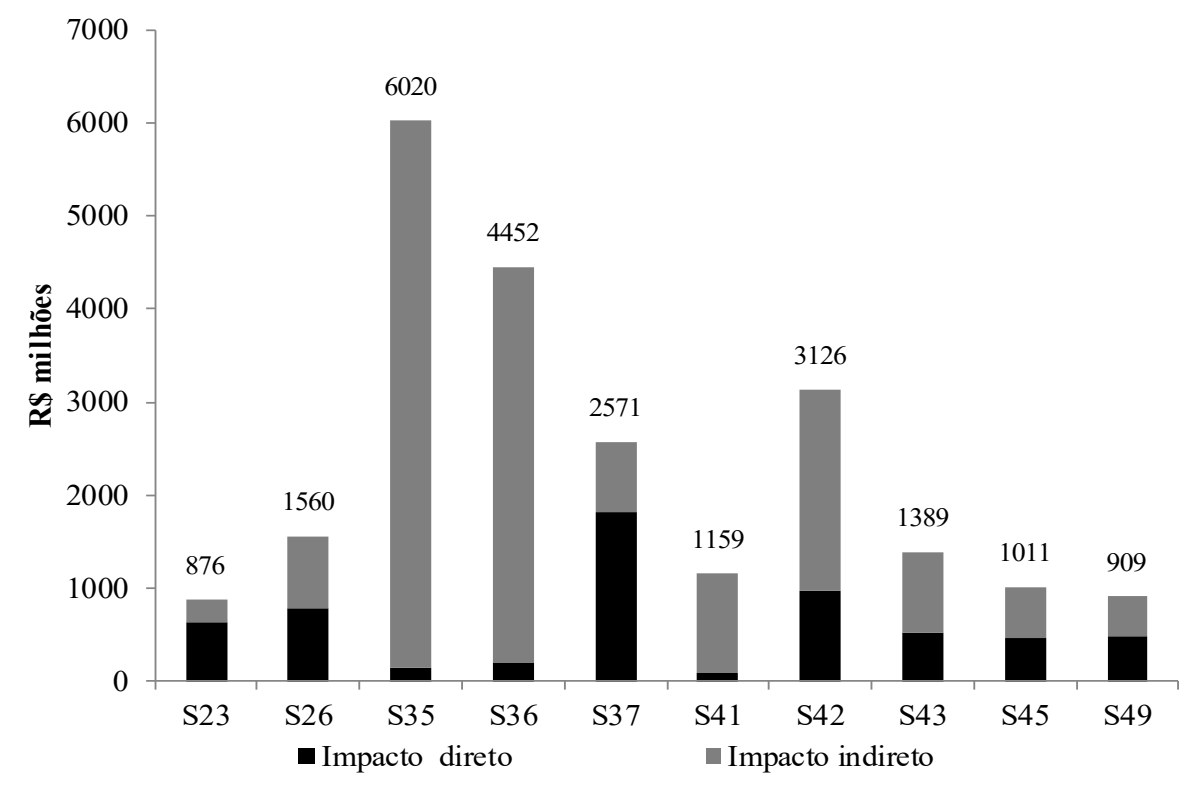

Fonte: elaboração própria.

14 No apêndice A, encontra-se uma tabela com todos os outros principais indicadores setoriais. 
Gráfico 7 - Setores com maior representação na expansão do emprego agregado

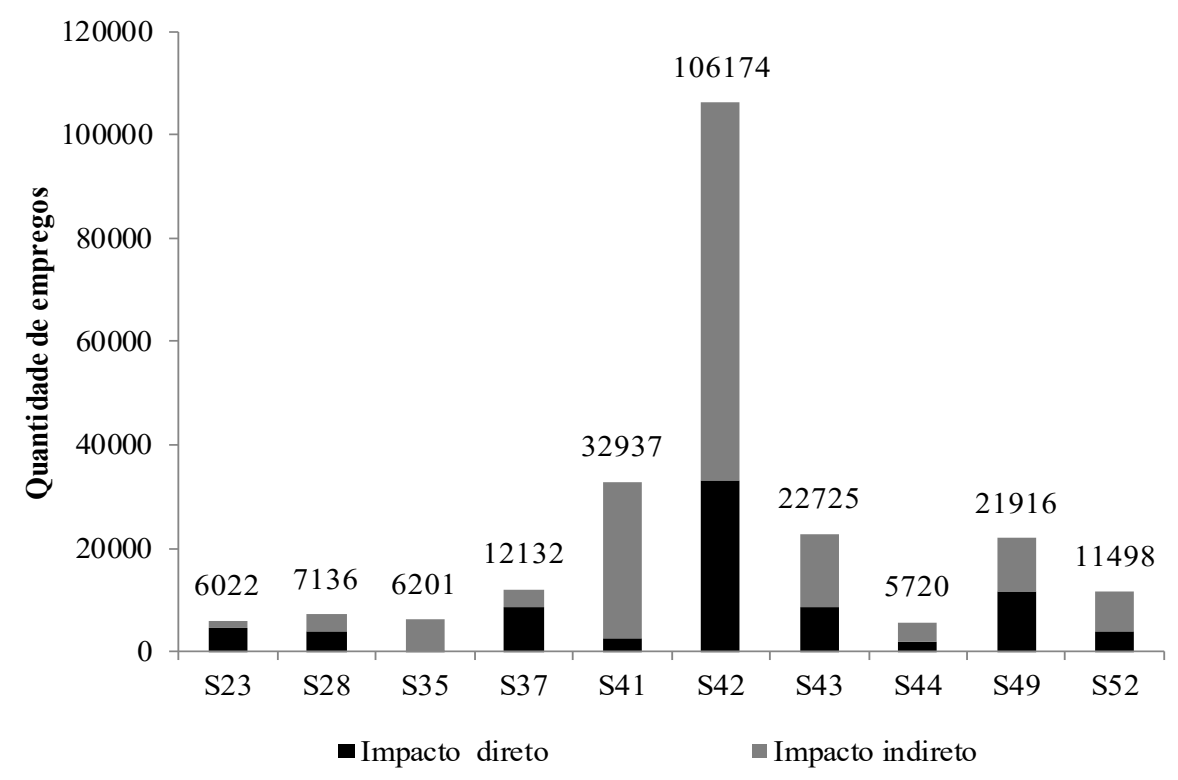

Fonte: elaboração própria.

Como observado no vetor de choque da Tabela 2, automóveis, caminhonetas e utilitários (S35) receberam $29,66 \%$ do total da variação inicial da demanda final e comércio (S4), 27,91\%. Já se esperava que tal setor fosse um dos mais beneficiados em termos de produção pelas inversões aeroportuárias, por estar diretamente relacionado ao setor de transportes. Ademais, para cada $\mathrm{R} \$ 1$ milhão na demanda total, esse setor emprega um trabalhador. A fração dos efeitos indiretos perante aos totais está na ordem de $98 \%$, corroborando a ideia de expressiva relação desse setor com o restante dos setores econômicos. Por produzir margens, o setor comércio é relativamente integrado no sistema produtivo brasileiro e é a sétima atividade que mais emprega na economia nacional, ou seja, para cada $R \$ 1$ milhão no valor bruto da produção (VBP), o comércio (S42) emprega 34 trabalhadores do mercado formal e informal. A parcela dos efeitos indiretos em relação ao impacto total denota a alta interação e integração dessa atividade econômica com os demais setores, isto é, 68\% dos efeitos totais representam efeitos indiretos (tanto para produção quanto para emprego).

Setores produtivos de fabricação de transporte apresentariam aumentos expressivos de produção na economia brasileira. Tratam-se de atividades econômicas mais diretamente vinculadas às expansões e operações da capacidade aeroportuária, conforme o vetor de choque da Tabela 2 As atividades de automóveis, caminho- 
netas e utilitários (S35), caminhões e ônibus (S36) e peças e acessórios para veículos automotores (S37) juntas atingem 51,49\% do valor total do choque inicial de investimento. Além de receberem grande parte da variação de demanda final, conforme o vetor de choques com a UPSI de transportes, automóveis, caminhonetas e utilitários (S35) e caminhões e ônibus (S36) produzem e absorvem grandes efeitos indiretos decorrentes das inversões aeroportuárias, acima 95\% do impacto total. A expansão das três atividades representaria 42,30\% da produção total, enquanto que, em termos de geração de emprego, alcançaria 7,78\% do total de ocupações geradas na economia brasileira. São setores que caracteristicamente apresentam uma baixa relação entre o número de ocupações e o montante do VBP.

Resumidamente, as 10 atividades produtivas que mais se beneficiariam com as inversões aeroportuárias representariam cerca de $75 \%$ do aumento da produção nacional, que, em termos monetários, implicaria um adicional de $\mathrm{R} \$ 23$ bilhões ao longo de 30 anos. No caso da produção, 72,91\% da expansão representam efeitos indiretos e os restantes, efeitos diretos. ${ }^{15}$ Nota-se que, para a maioria desses setores, os efeitos indiretos são maiores que os efeitos diretos. Assim, essas atividades econômicas produzem e absorvem grande parte dos efeitos de segunda ordem perante os choques de investimentos na economia, justamente por apresentarem maior integração e interação no sistema produtivo brasileiro. Se somadas, atingem $66 \%$ do valor total do choque inicial de investimento (ver Tabela 3).

Por sua vez, os 10 setores menos beneficiados pela expansão do investimento, em termos de produto, somados representariam 0,26\% do aumento total da produção (ver Gráfico 8). A possível justificativa se deve ao fato de que parte desses resultados reproduz os baixos valores (próximos de 0,00) de cada setor no vetor de choque, mas outra parte desses resultados pode ser explicada pela fraca interação que os referidos setores têm com aqueles que receberam mais com o choque. Ademais, essas atividades econômicas caracteristicamente podem ser mais ligadas ao consumo das famílias e do governo.

15 No apêndice B, encontra-se uma tabela com os impactos diretos e indiretos dos 55 setores, em termos de produção e emprego. 
Gráfico 8 - Os 10 setores econômicos menos beneficiados pelas inversões aeroportuárias (produção)

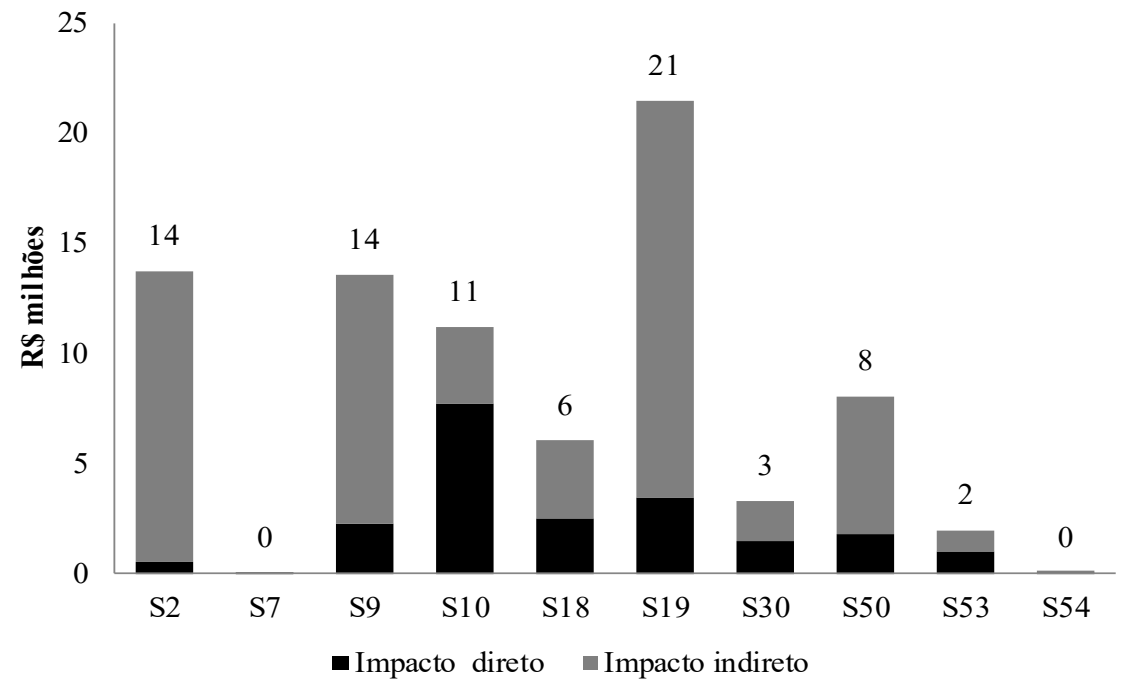

Fonte: elaboração própria.

Dos empregos que podem ser criados, os principais setores somados representariam $82 \%$ da geração de empregos devido à expansão das inversões (aproximadamente 232 mil) (ver Gráfico 7). O setor outros serviços (S52) é o que mais emprega mão de obra na economia brasileira, para cada $R \$ 1$ milhão de aumento na demanda final há 79 trabalhadores. Constatou-se que 67\% da expansão do emprego representam os efeitos indiretos e os $33 \%$ restantes, os efeitos diretos.

Por outro lado, os cinco setores que menos criariam empregos (ver Gráfico 9) têm baixa participação na estrutura de choque, por isso são menos favorecidos. Com exceção dos setores de educação pública (S53) e saúde pública (S54), os demais são aqueles que menos empregam na economia nacional. Os setores de refino de petróleo e coque (S14) e petróleo e gás natural (S3) são os menos intensivos em mão de obra, de acordo com seus coeficientes estruturais de emprego, que estão na ordem de 0,16 e 0,53, respectivamente. 
Gráfico 9 - Setores com menor representação na expansão do emprego agregado

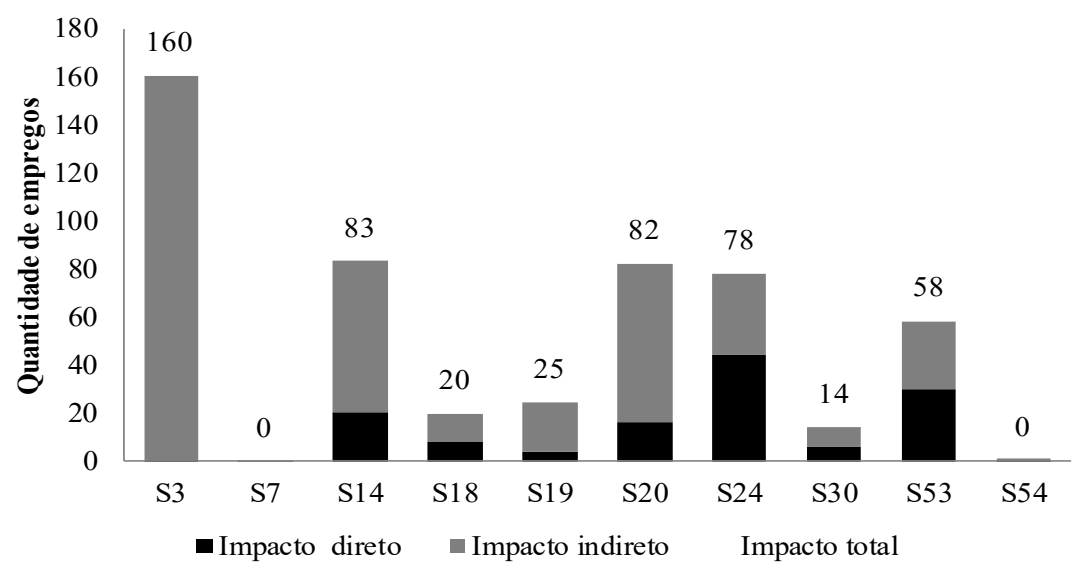

Fonte: elaboração própria.

\section{Considerações Finais}

O objetivo deste trabalho foi projetar os prováveis desdobramentos econômicos dos investimentos programados em um horizonte de 30 anos para a ampliação da capacidade dos aeroportos concedidos à iniciativa privada entre $2012 \mathrm{e}$ 2014. Os efeitos oriundos dessas inversões aeroportuárias foram analisados sobre os principais indicadores macroeconômicos e setoriais, quais sejam: PIB, produção nacional, emprego, impostos e importações.

Para atingir o objetivo, utilizou-se um modelo econômico de simulação que permite isolar os efeitos desses investimentos sobre a economia brasileira. Caracteristicamente, o MIP apresenta essa vantagem, além de considerar em uma análise estática as interações setoriais do sistema produtivo brasileiro. Utilizou-se uma MIP nacional para o ano de 2008, dimensionada em 55 setores econômicos.

O trabalho construiu um vetor de choque que reproduzisse, em alguma medida, o comportamento de alocação dos investimentos das atividades de transporte, as quais compreendem os aeroportos brasileiros. As informações de investimentos para os cinco aeroportos subjacentes ao processo de concessão iniciado em 2012 foram obtidas pela Secretaria de Aviação Civil (BRASIL, 2015c).

Os principais resultados projetados indicaram um aumento de $R \$ 11,3$ bilhões no PIB brasileiro e a possível criação de 282 mil empregos diretos e indiretos no país ao longo desses 30 anos. Nesse período, um choque de $R \$ 14,5$ bilhões geraria um aumento de aproximadamente $\mathrm{R} \$ 30,8$ bilhões na produção nacional. Diante do acréscimo de demanda de trabalhadores, haveria também variações 
positivas nas remunerações trabalhistas, cerca de $\mathrm{R} \$ 5$ bilhões. Por outro lado, a expansão da atividade econômica contribuiria para a arrecadação total de impostos. Ou melhor, projeta-se uma expansão de aproximadamente $\mathrm{R} \$ 1,6$ bilhão de receitas tributárias nesses 30 anos, cujo montante representa 8,05\% do valor investido. Além disso, as importações cresceriam, em 30 anos, $\mathrm{R} \$ 3,3$ bilhões, o que seria $16,74 \%$ do total de investimentos previstos.

Já em termos setoriais, notou-se que o setor de automóveis, caminhonetas e utilitários (S35) seria o mais beneficiado em termos de produção e o de comércio (S42) o que mais geraria emprego na economia brasileira. Ademais, nota-se que, para a maioria dos setores mais beneficiados, os efeitos indiretos foram maiores que os efeitos diretos, significando que esses setores têm maior poder de propagação dos efeitos das inversões aeroportuárias na economia.

A temática sobre concessões é recente, uma vez que a primeira rodada de leilão se deu em 2012 e a última em 2014, cujo aspecto denota que foi pouco explorada na área da economia aplicada. Umas das principais contribuições deste trabalho é fazer uma análise quantitativa em um sistema de setores interdependentes que detalha os desdobramentos das concessões aeroportuárias. Com isso, pode-se mapear as transmissões, distribuições e intensidades desses desdobramentos no sistema produtivo brasileiro sobre certos indicadores econômicos. Nesse sentido, as projeções poderiam ser de grande interesse para o debate em curso sobre as concessões de infraestrutura de transporte, especialmente para os formuladores de políticas públicas e dirigentes das empresas concessionárias ao apontar os efeitos econômicos e os setores mais beneficiados e que mais geram e absorvem efeitos indiretos na economia brasileira.

Além disso, os efeitos projetados sinalizaram um provável aumento da receita tributária no orçamento da administração pública. Além do aumento da arrecadação de impostos em razão da expansão da atividade econômica, e não pela expansão da carga tributária, o governo se beneficiaria com a política de concessões aeroportuárias por transferir a responsabilidade da administração desse tipo de infraestrutura à iniciativa privada, mesmo que esta explore as operações em um horizonte de 30 anos. Dessa forma, este estudo aponta para o governo os benefícios econômicos das inversões previstas em aeroportos recentemente concedidos.

Dentro de um contexto de agenda de pesquisa, um modelo de equilíbrio geral poderia ser aplicado de forma a considerar efeitos competitivos de preços e movimentos em parte dos usuários da demanda final. Poderiam fazer parte da análise novos aeroportos concedidos e como as concessões afetariam o comportamento de consumo das famílias no longo prazo, pois quedas nas tarifas aéreas em função da redução dos custos operacionais nos aeroportos poderiam influenciar uma substituição imperfeita em favor do transporte aéreo e em detrimento do transporte rodoviário interestadual de passageiros. 


\section{Referências}

ALPEROVICH, G.; MACHNES, Y. The role of wealth in demand for international air travel. Journal of Transport Economics and Policy, v. 28, n. 2, p. 163-173, 1994.

ANAC - AGÊNCIA NACIONAL DE AVIAÇÃO CIVIL. Dados do anuário do transporte aéreo. Brasília: ANAC, 2015. Disponível em: https://www.anac.gov.br/assuntos/dados-e-estatisticas/ mercado-de-transporte-aereo/anuario-do-transporte-aereo/dados-do-anuario-do-transporte-aereo. Acesso em: 21 abr. 2020.

ANDRADE, M. Investimentos realizados no Aero GRU. Mensagem recebida por < marcelacsc@hotmail.com> em 29 set. 2015.

BANCO MUNDIAL. The World Bank. [2014]. Disponível em: http://www.worldbank.org. Acesso em: 26 nov. 2014.

BANISTER, D.; BERECHMAN, Y. Transport investment and the promotion of economic growth. Journal of Transport Geography, v. 9, n. 3, p. 209-218, 2001.

BETARELLI, A.; ASSIS, C. Concessões dos aeroportos, embarque imediato. Tribuna de Minas, 2014. Disponível em: http://www.tribunademinas.com.br/concessoes-dos-aeroportosembarque-imediato/. Acesso em: 31 out. 2014.

BETARELLI JUNIOR, A. A.; PEROBELLI, F. S.; VALE, V. A. Estimação da matriz de insumoproduto de 2011 e análise do sistema produtivo brasileiro. Texto para Discussão - PPGE UFJF, n. 001/2015, 2015. Disponível em: http://www.ufjf.br/poseconomia/files/2015/06/001-15.pdf. Acesso em: 21 abr. 2020.

BIELSCHOWSKY, P. CUSTÓDIO, M. C.; A evolução do setor de transporte aéreo brasileiro. Novo Enfoque, v. 13, n. 13, p. 72-93, 2011.

BORGES, J. P. R. Impactos econômicos da expansão do metrô de belo horizonte: uma aplicação do modelo insumo-produto. 2011. Trabalho de Conclusão de Curso (Graduação em Ciências Econômicas) - Universidade Federal de Minas Gerais, Belo Horizonte, 2011.

BRASIL. Ministério do Planejamento. Programa de investimento em logística. Brasília, DF: Presidência da República, 2015a. Disponível em: http://www.logisticabrasil.gov.br/. Acesso em: 12 nov. 2015.

BRASIL. Palácio do Planalto. Concessões vão acelerar investimentos na infraestrutura aeroportuária. Palácio do Planalto, Brasília, 2015b. Disponível em: http:/www2.planalto.gov.br/ acompanhe-o-planalto/caderno-destaques/marco-2012/desenvolvimento-do-setor-aereo. Acesso em: 09 out. 2015.

BRASIL. Secretaria de Aviação Civil. Concessões. Brasília, DF: Presidência da República, [2015c]. Disponível em: http://www.aviacao.gov.br/assuntos/concessoes-de-aeroportos . Acesso em: 09 out. 2015. 
BRASIL. Ministério da Infraestrutura: Infraero. Concessão de aeroportos. Brasília, DF: Presidência da República, [2016]. Disponível em: https://transparencia.infraero.gov.br/concessao-de-uso-de-areas/. Acesso em: 26 fev. 2016.

BUTTON, K. Transport economics. 3 ed. Cheltenham: Edward Elgar, 2010.

CASTRO JÚNIOR, O. A. Análise comparativa da regulação dos transportes aéreos nos Estados Unidos e Brasil: breves notas. Journal of Transport Literature, v. 5, n. 2, p. 163-174, 2011.

CNT - CONFEDERAÇÃO NACIONAL DO TRANSPORTE. Transporte e economia - transporte aéreo de passageiros. CNT, Brasília, [2015]. Disponível em: https://cnt.org.br/transporte-economia-trasporte-aereo-passageiros. Acesso em: 12 nov. 2015.

DOMINGUES, E. P.; CARVALHO, T. S. Análise dos impactos econômicos dos desembolsos do BDMG nos anos 2005, 2009 e 2010 em Minas Gerais. Cadernos BDMG, n. 21, p. 7-54, 2012.

HIRSCHMAN, A. A estratégia do desenvolvimento econômico. Rio de Janeiro: Fundo de cultura, 1961.

INSTITUTO BRASILEIRO DE GEOGRAFIA E ESTATÍSTICA (IBGE). Sistema de Contas Nacionais: Brasil referência 2010-2011. Rio de Janeiro: IBGE, 2015. (Contas Nacionais, n. 44).

MANKIW, N. G. Introdução à economia. 5 ed. São Paulo: Cengage Learning, 2009.

MARCHETTI, D. S.; SOUZA, R. M. A. T.; ÁVILA, J. R. G.; CASTRO, M. S. Aspectos de competitividade do setor aéreo (Modal Aéreo II). Informe Infraestrutura - Banco Nacional de Desenvolvimento Econômico e Social, n. 42, p. 1-8, 2001 a.

MARCHETTI, D. S.; SOUZA, R. M. A. T.; ÁVILA, J. R. G.; CASTRO, M. S. Infraestrutura aeroportuária: fator de competitividade econômica (modal aéreo III). Informe Infraestrutura - Banco Nacional de Desenvolvimento Econômico e Social, n. 46, p. 1-8, 2001 b.

MARTINEZ, T. S. Estimação das tabelas auxiliares de impostos e margens da matriz de insumo-produto com mínima perda de informação: algoritmo RAWS. Pesquisa e Planejamento Econômico. v. 44, n. 2, p. 289-336, 2014 a.

MARTINEZ, T. S. Método RAWS/RAW para estimação anual da matriz de insumo-produto. Brasília: Ipea, 2014b.

MARTINEZ, T. S. Método RAWS/RAW para estimação anual da matriz de insumo-produto. Brasília: Ipea, 2015.

MATERA, R. R. T. O desafio logístico na implantação de um aeroporto indústria no Brasil. Journal of Transport Literature, v. 6, n. 4, p. 190-214, 2012.

MIGUEZ, T.; FREITAS, F. N. P.; SQUEFF, G. C.; VASCONCELOS, L. F.; MOREIRA, T. M. Uma proposta metodológica para a estimação da matriz de absorção de investimentos para o período 2000-2009. Brasília: Ipea, 2014. 
MILLER, R. E.; BLAIR, P. D. Input-outpu analysus: foundations and extensions. 2. ed. Nova Iorque: Cambridge University Press, 2009.

SALGADO, L. H.; VASSALLO, M. D.; OLIVEIRA, A. V. M. Regulação, políticas setoriais, competitividade e formação de preços: considerações sobre o transporte aéreo no Brasil. Journal of Transport Literature, v. 4, n. 1, p. 7-48, 2010.

SENADO FEDERAL. Siga Brasil [2018]. Disponível em: https://www12.senado.leg.br/orcamento/sigabrasil. Acesso em: dez. 2018.

SILVA, G. J. C.; FORTUNATO, W. L. L. Infraestrutura e crescimento: uma avaliação do caso brasileiro no período 1985-1998. In: FÓRUM BNB DE DESENVOLVIMENTO XII ENCONTRO REGIONAL DE ECONOMIA, 2007, Fortaleza. Anais eletrônicos [...]. Fortaleza: Banco do Nordeste do Brasil, 2007.

TOYOSHIMA, S.; FERREIRA, M. J. Encadeamentos do setor de transportes na economia brasileira. Planejamento e Políticas Públicas, n. 25, p. 139-166, 2002.

ZIMMERMANN, N.; OLIVEIRA, A. V. M. Liberalização econômica e universalização do acesso no transporte aéreo: é possível conciliar livre mercado com metas sociais e ainda evitar gargalos de infraestrutura. Journal of Transport Literature, v. 6, n. 4, p. 82-100, 2012.

\section{Apêndice A - Resultados de Indicadores Setoriais Selecionados (em $\mathrm{R} \$$ milhões)}

\begin{tabular}{llccccc}
\hline Cod & Setores & PIB & Imp Ind & Import & Remun & VA \\
\hline S1 & Agricultura, silvicultura, exploração florestal & 43.6 & 2.4 & 1.6 & 11.2 & 41.2 \\
S2 & Pecuária e pesca & 7.3 & 0.6 & 0.2 & 3.0 & 6.7 \\
S3 & Petróleo e gás natural & 156.5 & 6.1 & 23.6 & 30.1 & 150.5 \\
S4 & Minério de ferro & 78.0 & 3.2 & 2.9 & 8.0 & 74.8 \\
S5 & Outros da indústria extrativa & 37.0 & 3.0 & 3.8 & 13.6 & 34.0 \\
S6 & Alimentos e bebidas & 12.2 & 2.3 & 1.9 & 6.1 & 9.8 \\
S7 & Produtos do fumo & 0.0 & 0.0 & 0.0 & 0.0 & 0.0 \\
S8 & Têxteis & 15.9 & 1.5 & 3.4 & 6.6 & 14.5 \\
S9 & Artigos do vestuário e acessórios & 6.2 & 0.6 & 0.7 & 2.9 & 5.6 \\
S10 & Artefatos de couro e calçados & 3.7 & 0.5 & 0.7 & 2.7 & 3.3 \\
S11 & Produtos de couro e calçados & 37.4 & 2.7 & 1.6 & 16.4 & 34.7 \\
S12 & Celulose e produtos de papel & 36.1 & 4.1 & 8.4 & 16.6 & 32.0 \\
S13 & Jornais, revistas, discos & 55.1 & 2.5 & 6.8 & 22.1 & 52.6 \\
S14 & Refino de petróleo e coque & 43.8 & 32.4 & 117.5 & 14.3 & 11.5 \\
S15 & Álcool & 19.5 & 0.9 & 0.3 & 6.3 & 18.6 \\
S16 & Produtos químicos & 58.3 & 12.2 & 98.9 & 22.2 & 46.1 \\
S17 & Fabricação de resina e elastômeros & 41.1 & 10.0 & 25.2 & 18.6 & 31.1 \\
S18 & Produtos farmacêuticos & 3.0 & 0.1 & 0.7 & 1.2 & 2.8 \\
S19 & Defensivos agrícolas & 4.6 & 0.9 & 3.7 & 1.9 & 3.7 \\
S20 & Perfumaria, higiene e limpeza & 5.3 & 0.5 & 1.7 & 2.2 & 4.8 \\
\hline & & & & & &
\end{tabular}

Continua... 
Conclusão.

\begin{tabular}{|c|c|c|c|c|c|c|}
\hline Cod & Setores & PIB & Imp Ind & Import & Remun & VA \\
\hline S21 & Tintas, vernizes, esmaltes e lacas & 26.0 & 2.8 & 19.3 & 14.2 & 23.2 \\
\hline S22 & Produtos e prepardps químicos diversos & 13.8 & 2.1 & 9.2 & 7.7 & 11.7 \\
\hline S23 & Artigos de borracha e plástico & 274.1 & 31.8 & 96.9 & 157.8 & 242.3 \\
\hline S24 & Cimento & 12.2 & 1.4 & 3.7 & 4.3 & 10.8 \\
\hline S25 & Outros produtos de minerais não-metálicos & 84.3 & 5.7 & 13.0 & 47.0 & 78.6 \\
\hline S26 & Fabricação de aço e derivados & 511.4 & 55.0 & 200.1 & 128.8 & 456.4 \\
\hline S27 & Metalurgia de metais não-ferrosos & 65.7 & 8.7 & 42.0 & 28.0 & 57.1 \\
\hline S28 & $\begin{array}{l}\text { Produtos de meta - exclusive máquinas e } \\
\text { equip. }\end{array}$ & 264.0 & 18.9 & 33.0 & 120.4 & 245.2 \\
\hline S29 & $\begin{array}{l}\text { Máquinas e equip. - inclusive manut. e } \\
\text { reparos }\end{array}$ & 213.1 & 24.2 & 55.3 & 118.0 & 188.9 \\
\hline S30 & Eletrodomésticos & 1.0 & 0.1 & 0.2 & 0.5 & 0.9 \\
\hline S31 & Escritório e equipamentos de informática & 56.6 & 22.5 & 94.5 & 23.1 & 34.1 \\
\hline S32 & Máquinas, aparelhos e materiais elétricos & 180.5 & 21.4 & 70.8 & 103.0 & 159.0 \\
\hline S33 & $\begin{array}{l}\text { Material eletrônico e equip. de } \\
\text { comunicações }\end{array}$ & 28.3 & 7.4 & 42.1 & 15.4 & 21.0 \\
\hline S34 & $\begin{array}{l}\text { Aparellhos medico-hospitalar, medida e } \\
\text { óptico }\end{array}$ & 51.0 & 2.4 & 12.5 & 17.7 & 48.6 \\
\hline S35 & Automóveis, caminhonetas e utilitários & 1004.6 & 320.4 & 957.7 & 603.2 & 684.1 \\
\hline S36 & Caminhões e ônibus & 808.6 & 239.7 & 857.7 & 414.7 & 568.9 \\
\hline S37 & $\begin{array}{l}\text { Peças e acessórios para veículos } \\
\text { automotores }\end{array}$ & 772.2 & 81.1 & 141.4 & 469.8 & 691.1 \\
\hline S38 & Outros equipamentos de transporte & 155.4 & 25.4 & 119.8 & 91.2 & 130.0 \\
\hline S39 & Móveis e produtos das indústrias diversas & 62.2 & 6.2 & 7.8 & 22.2 & 55.9 \\
\hline $\mathrm{S} 40$ & Eletricidade e gás, água, esgoto e limpeza & 366.9 & 12.5 & 31.4 & 83.3 & 354.3 \\
\hline S41 & Construção & 686.0 & 82.5 & 36.1 & 218.9 & 603.5 \\
\hline $\mathrm{S} 42$ & Comércio & 2310.5 & 99.1 & 40.9 & 976.3 & 2211.5 \\
\hline $\mathrm{S} 43$ & Transporte, armazenagem e correio & 725.9 & 42.2 & 51.3 & 322.3 & 683.7 \\
\hline S44 & Serviços de informação & 324.6 & 19.1 & 25.5 & 109.7 & 305.5 \\
\hline S45 & Intermediação financeira e seguros & 675.6 & 37.4 & 20.4 & 257.2 & 638.2 \\
\hline S46 & Serviços imibiliários e aluguel & 148.6 & 0.9 & 0.4 & 5.5 & 147.7 \\
\hline S47 & Serviços de manutenção e reparação & 48.3 & 3.4 & 1.5 & 13.1 & 44.8 \\
\hline S48 & Serviços de alojamento e alimentação & 31.8 & 4.6 & 0.5 & 11.2 & 27.2 \\
\hline S49 & Serviços pretados à empresas & 596.0 & 42.8 & 19.4 & 319.9 & 553.2 \\
\hline S50 & Educação mercantil & 5.3 & 0.4 & 0.1 & 4.6 & 4.9 \\
\hline S51 & Saúde mercantil & 12.9 & 1.1 & 0.6 & 7.0 & 11.9 \\
\hline S52 & Outros serviços & 97.6 & 7.7 & 2.9 & 66.5 & 89.9 \\
\hline S53 & Educação pública & 1.6 & 0.1 & 0.0 & 1.4 & 1.5 \\
\hline S54 & Saúde pública & 0.0 & 0.0 & 0.0 & 0.0 & 0.0 \\
\hline \multirow[t]{2}{*}{ S55 } & Administração pública e seguridade social & 56.8 & 3.4 & 0.7 & 46.1 & 53.4 \\
\hline & Total & 11338.2 & 1320.8 & 3312.5 & 5035.9 & 10017.3 \\
\hline
\end{tabular}

Fonte: Elaborado pelos autores. 


\begin{tabular}{|c|c|c|c|c|c|c|c|}
\hline \multirow[b]{2}{*}{ Código } & \multirow[b]{2}{*}{ Setores } & \multicolumn{3}{|c|}{ Produção } & \multicolumn{3}{|c|}{ Emprego } \\
\hline & & Direto & Indireto & Total & Direto & Indireto & Total \\
\hline S1 & $\begin{array}{l}\text { Agricultura, silvicultura, exploração } \\
\text { florestal }\end{array}$ & 2.85 & 68.65 & 71.50 & 186.67 & 4502.23 & 4688.90 \\
\hline $\mathrm{S} 2$ & Pecuária e pesca & 0.49 & 13.25 & 13.74 & 26.16 & 706.16 & 732.32 \\
\hline S3 & Petróleo e gás natural & 0.32 & 299.58 & 299.90 & 0.17 & 160.22 & 160.39 \\
\hline S4 & Minério de ferro & 1.16 & 131.02 & 132.18 & 1.19 & 134.62 & 135.81 \\
\hline S5 & Outros da indústria extrativa & 11.52 & 75.43 & 86.95 & 115.36 & 755.10 & 870.46 \\
\hline S6 & Alimentos e bebidas & 6.51 & 52.02 & 58.53 & 44.24 & 353.28 & 397.51 \\
\hline S7 & Produtos do fumo & 0.00 & 0.00 & 0.01 & 0.00 & 0.01 & 0.01 \\
\hline S8 & Têxteis & 7.53 & 30.81 & 38.34 & 180.64 & 739.48 & 920.12 \\
\hline S9 & Artigos do vestuário e acessórios & 2.29 & 11.25 & 13.54 & 113.69 & 557.60 & 671.29 \\
\hline S10 & Artefatos de couro e calçados & 7.73 & 3.49 & 11.22 & 184.12 & 83.12 & 267.24 \\
\hline S11 & Produtos de couro e calçados & 36.16 & 49.21 & 85.37 & 758.87 & 1032.85 & 1791.72 \\
\hline $\mathrm{S} 12$ & Celulose e produtos de papel & 29.37 & 80.38 & 109.75 & 128.29 & 351.17 & 479.46 \\
\hline S13 & Jornais, revistas, discos & 12.54 & 90.54 & 103.08 & 135.95 & 981.75 & 1117.70 \\
\hline S14 & Refino de petróleo e coque & 128.61 & 407.08 & 535.69 & 19.96 & 63.19 & 83.15 \\
\hline S15 & Álcool & 9.53 & 34.12 & 43.64 & 58.80 & 210.62 & 269.42 \\
\hline S16 & Produtos químicos & 8.48 & 302.22 & 310.70 & 10.39 & 370.42 & 380.8 \\
\hline S17 & Fabricação de resina e elastômeros & 13.61 & 235.38 & 249.00 & 14.15 & 244.67 & 258.8 \\
\hline S18 & Produtos farmacêuticos & 2.47 & 3.55 & 6.02 & 8.14 & 11.70 & 19.8 \\
\hline S19 & Defensivos agrícolas & 3.47 & 17.99 & 21.46 & 3.96 & 20.54 & 24.5 \\
\hline S20 & Perfumaria, higiene e limpeza & 3.37 & 13.86 & 17.23 & 16.05 & 66.06 & 82.1 \\
\hline S21 & Tintas, vernizes, esmaltes e lacas & 63.15 & 21.62 & 84.78 & 204.00 & 69.85 & 273.9 \\
\hline S22 & Produtos e prepardps químicos diversos & 4.33 & 45.55 & 49.87 & 25.19 & 265.13 & 290.3 \\
\hline $\mathrm{S} 23$ & Artigos de borracha e plástico & 644.89 & 231.14 & 876.03 & 4433.45 & 1589.00 & 6022.4 \\
\hline S24 & Cimento & 25.41 & 19.29 & 44.69 & 44.38 & 33.69 & 78.1 \\
\hline S25 & $\begin{array}{l}\text { Outros produtos de minerais não- } \\
\text {-metálicos }\end{array}$ & 142.87 & 77.99 & 220.85 & 2174.68 & 1187.08 & 3361.8 \\
\hline S26 & Fabricação de aço e derivados & 792.28 & 767.99 & 1560.27 & 1000.74 & 970.06 & 1970.8 \\
\hline S27 & Metalurgia de metais não-ferrosos & 79.61 & 157.91 & 237.51 & 264.25 & 524.15 & 788.4 \\
\hline $\mathrm{S} 28$ & $\begin{array}{l}\text { Produtos de meta - exclusive máquinas } \\
\text { e eq }\end{array}$ & 343.34 & 292.49 & 635.83 & 3853.57 & 3282.89 & 7136.5 \\
\hline S29 & $\begin{array}{l}\text { Máquinas e equip. - inclusive manut. e } \\
\text { reparos }\end{array}$ & 215.32 & 412.92 & 628.24 & 1209.70 & 2319.89 & 3529.6 \\
\hline S30 & Eletrodomésticos & 1.43 & 1.86 & 3.29 & 6.15 & 8.00 & 14.2 \\
\hline S31 & $\begin{array}{l}\text { Escritório e equipamentos de informá- } \\
\text { tica }\end{array}$ & 1.47 & 237.10 & 238.57 & 3.59 & 578.82 & 582.4 \\
\hline S32 & Máquinas, aparelhos e materiais elétricos & 349.81 & 218.26 & 568.07 & 1875.10 & 1169.97 & 3045.1 \\
\hline S33 & $\begin{array}{l}\text { Material eletrônico e equip. de comu- } \\
\text { nicações }\end{array}$ & 37.94 & 122.21 & 160.15 & 102.80 & 331.18 & 434.0 \\
\hline S34 & Aps medico-hospitalar, medida e óptico & 27.01 & 62.97 & 89.99 & 243.69 & 568.13 & 811.8 \\
\hline S35 & Automóveis, caminhonetas e utilitários & 140.47 & 5879.48 & 6019.95 & 144.70 & 6056.72 & 6201.4 \\
\hline S36 & Caminhões e ônibus & 212.03 & 4239.75 & 4451.77 & 173.46 & 3468.55 & 3642.0 \\
\hline S37 & $\begin{array}{l}\text { Peças e acessórios para veículos auto- } \\
\text { motores }\end{array}$ & 1815.30 & 755.34 & 2570.64 & 8567.53 & 3564.92 & 12132.4 \\
\hline S38 & Outros equipamentos de transporte & 80.96 & 509.38 & 590.33 & 275.56 & 1733.78 & 2009.3 \\
\hline S39 & Móveis e produtos das indústrias diversas & 6.23 & 128.35 & 134.58 & 131.84 & 2715.93 & 2847.8 \\
\hline
\end{tabular}

Continua... 


\begin{tabular}{|c|c|c|c|c|c|c|c|}
\hline \multirow[b]{2}{*}{ Código } & \multirow[b]{2}{*}{ Setores } & \multicolumn{3}{|c|}{ Produção } & \multicolumn{3}{|c|}{ Emprego } \\
\hline & & Direto & Indireto & Total & Direto & Indireto & Total \\
\hline $\mathrm{S} 40$ & $\begin{array}{l}\text { Eletricidade e gás, água, esgoto e lim- } \\
\text { peza urb. }\end{array}$ & 199.00 & 524.34 & 723.34 & 493.90 & 1301.36 & 1795.3 \\
\hline S41 & Construção & 86.45 & 1072.25 & 1158.70 & 2457.33 & 30479.62 & 32937.0 \\
\hline $\mathrm{S} 42$ & Comércio & 978.45 & 2147.76 & 3126.22 & 33230.71 & 72943.48 & 106174.2 \\
\hline S43 & Transporte, armazenagem e correio & 518.91 & 870.17 & 1389.08 & 8489.15 & 14235.44 & 22724.6 \\
\hline S44 & Serviços de informação & 183.49 & 419.84 & 603.33 & 1739.65 & 3980.41 & 5720.1 \\
\hline S45 & Intermediação financeira e seguros & 465.24 & 545.39 & 1010.63 & 1587.60 & 1861.11 & 3448.7 \\
\hline S46 & Serviços imibiliários e aluguel & 45.95 & 113.46 & 159.41 & 132.96 & 328.32 & 461.3 \\
\hline S47 & Serviços de manutenção e reparação & 11.23 & 49.80 & 61.03 & 617.69 & 2739.95 & 3357.6 \\
\hline S48 & Serviços de alojamento e alimentação & 26.43 & 35.53 & 61.96 & 938.38 & 1261.50 & 2199.9 \\
\hline S49 & Serviços pretados à empresas & 477.17 & 432.30 & 909.46 & 11498.88 & 10417.54 & 21916.4 \\
\hline S50 & Educação mercantil & 1.80 & 6.26 & 8.07 & 56.79 & 197.53 & 254.3 \\
\hline S51 & Saúde mercantil & 6.68 & 15.33 & 22.01 & 134.49 & 308.76 & 443.3 \\
\hline S52 & Outros serviços & 47.16 & 96.81 & 143.98 & 3766.54 & 7731.62 & 11498.2 \\
\hline S53 & Educação pública & 1.00 & 0.96 & 1.96 & 29.65 & 28.72 & 58.4 \\
\hline S54 & Saúde pública & 0.01 & 0.01 & 0.02 & 0.20 & 0.18 & 0.4 \\
\hline \multirow[t]{3}{*}{ S55 } & $\begin{array}{l}\text { Administração pública e seguridade } \\
\text { social }\end{array}$ & 32.50 & 51.31 & 83.80 & 408.91 & 645.61 & 1054.5 \\
\hline & Total & 8353 & 22483 & 30836 & 92324 & 190244 & 282568 \\
\hline & Participação (\%) & 27.09 & 72.91 & 100 & 32.67 & 67.33 & 100 \\
\hline
\end{tabular}

Fonte: Elaborado pelos autores.

\section{Autor correspondente:}

Admir Antonio Betarelli Júnior

E-mail: abetarelli@gmail.com

Recebido em: 19/12/2016.

Aceito em: 17/12/2018. 